\title{
Hydrological Validation of a Radar-Based Nowcasting Technique
}

\author{
Marc Berenguer, Carles Corral, Rafael Sánchez-Diezma, and Daniel Sempere-Torres \\ Grup de Recerca Aplicada en Hidrometeorologia, Universitat Politècnica de Catalunya, Barcelona, Spain
}

(Manuscript received 16 November 2004, in final form 21 February 2005)

\begin{abstract}
Nowcasting precipitation is a key element in the anticipation of floods in warning systems. In this framework, weather radars are very useful because of the high resolution of their measurements both in time and space. The aim of this study is to assess the performance of a recently proposed nowcasting technique (S-PROG) from a hydrological point of view in a Mediterranean environment. S-PROG is based on the advection of weather radar fields according to the motion field derived with an algorithm based on tracking radar echoes by correlation (TREC), and it has the ability of filtering out the most unpredictable scales of these fields as the forecasting time increases. Validation of this nowcasting technique was done from two different perspectives: (i) comparing forecasted precipitation fields against radar measurements, and (ii) by means of a distributed rainfall runoff model, comparing hydrographs simulated with a hydrological model using rainfall fields forecasted by S-PROG against hydrographs generated with the model using the entire series of radar measurements. In both cases, results obtained by a simpler nowcasting technique are used as a reference to evaluate improvements. Validation showed that precipitation fields forecasted with S-PROG seem to be better than fields forecasted using simpler techniques. Additionally, hydrological validation led the authors to point out that the use of radar-based nowcasting techniques allows the anticipation window in which flow estimates are forecasted with enough quality to be sensibly extended.
\end{abstract}

\section{Introduction}

Floods are the most important natural hazard in Mediterranean areas, and anticipation of extreme events is of vital importance for flood warning and emergency management. However, extending the anticipation with which floods can be forecasted is particularly difficult because of the high spatial and temporal variability of precipitation and because of the fast response of the basins that, in general, have a high degree of urbanization.

In this framework, a number of studies (Wilson et al. 1979; Wyss et al. 1990; Pessoa et al. 1993; SempereTorres et al. 1999) have shown that weather radar information may be valuable in providing accurate flow estimates using a rainfall-runoff model thanks to the good spatial and temporal resolution of radar measurements that capture the structure of precipitation fields.

Corresponding author address: Marc Berenguer, Grup de Recerca Aplicada en Hidrometeorologia, Universitat Politècnica de Catalunya, Gran Capità, 2-4 (edifici Nexus), desp. 102, Barcelona E-08034, Spain.

E-mail: berengue@grahi.upc.edu
To extend the anticipation with which flow estimates are forecasted with a hydrological model, it was found interesting to couple the model with a nowcasting technique using radar scans.

An extensive review and classification of existing nowcasting techniques can be found in Wilson et al. (1998) and Wilson (2003). They propose a classification of these techniques into three categories:

- algorithms based on the extrapolation of the most recent observations,

- conceptual models of convection initiation and dissipation, and

- nowcasting methods based on explicit numerical prediction of thunderstorms.

Some nowcasting techniques that could be included into the first group of the classification were recently developed (Germann and Zawadzki 2002; Seed 2003). These techniques were tested using radar data, and, from the point of view of the forecasted precipitation fields, they turn out to improve the results obtained with Lagrangian persistence (which consists of simply advecting the most recently measured radar scan according to an estimation of the motion field). The two techniques developed by Germann and Zawadzki 
(2002) and Seed (2003) take into account that the smallsize patterns of the precipitation field decorrelate faster than those that have larger scales. Therefore, they propose to filter out the small-scale patterns as the forecasting time increases. This was already pointed out by Bellon and Zawadzki (1994): they found that increasing the spatial averaging by means of a power-law function of the forecasting time produced optimum forecasts.

The main purpose of the present study was to assess the performance of one of these nowcasting techniques (S-PROG; Seed 2003) in the area of Barcelona (northeast Spain) from two different perspectives: (a) in terms of the forecasted precipitation fields and (b) in terms of the forecasted flows simulated with a distributed rainfall-runoff model.

This second point of view matches with the concept of hydrological validation. This concept consists of assessing the performance of any technique applied to improve precipitation estimates from the perspective of the discharges simulated by a rainfall-runoff model. In general, as these models do a kind of integration of the precipitation fields over the basin, they are significantly affected by biases in the mean areal precipitation (Obled et al. 1994; Vieux and Bedient 2004). However, a good description of the distribution of the precipitation over the basin is expected to improve the quality of simulated hydrographs as well [e.g., Giannoni et al. (2003) concluded that both structure and precipitation motion play an important role in determining the timing of the response of the studied basin].

Previous studies validated different techniques for precipitation estimation from the point of view of its effects in flow simulation. A number of works evaluated the impact of both temporal and spatial resolutions of the rainfall field (Krajewski et al. 1991; Pessoa et al. 1993; Obled et al. 1994; Ogden and Julien 1994; Faurès et al. 1995; Shah et al. 1996; Winchell et al. 1998; Carpenter et al. 2001). Other studies focused on evaluating the influence of different quantitative precipitation estimation (QPE) algorithms used for improving rainfall estimates from radar measurements on the output hydrographs simulated by different rainfall-runoff models (see Pessoa et al. 1993; Winchell et al. 1998; Borga et al. 2000; Sun et al. 2000; Sánchez-Diezma et al. 2001a; Borga 2002; Pellarin et al. 2002; Gourley and Vieux 2003; Kouwen et al. 2004; Vieux and Bedient 2004). One important aspect in hydrological validation is which reference hydrograph is used to compare simulated flows with, in order to decide if any improvement is achieved with any of the tested configurations. The main sources of reference hydrographs are flow observations (Obled et al. 1994; Sun et al. 2000; Carpenter et al. 2001; Borga 2002; Gourley and Vieux 2003; Kouwen et al. 2004; Vieux and Bedient 2004) and hydrographs computed with the hydrological model using a reference series of precipitation fields, from rain gauges (Borga 2002; Pellarin et al. 2002) or in a simulation framework (Winchell et al. 1998; Sánchez-Diezma et al. 2001a).

On the other hand, a few papers focused on the effect of using short-term forecasted precipitation fields based on weather radar data jointly with a rainfall-runoff model. Mecklenburg et al. (2001) compared the results achieved using a set of different nowcasting techniques to generate the precipitation inputs for a distributed rainfall-runoff model. In a different study, Dolcine et al. (2001) tested the quality of hydrographs obtained by a lumped model with rainfall inputs forecasted with a technique that simulated the evolution of the vertical integrated liquid water using radar and satellite measurements. This study showed that the use of the forecasting technique generated better hydrographs than supposing Eulerian persistence (which simply consists of keeping stationary the last radar scan as forecast).

In the present study, the hydrograph simulated by the distributed rainfall-runoff model DiCHiTop [see a description in Corral et al. (2001)] using the full series of observed radar fields was chosen as the reference hydrograph. Working in such a simulation environment allowed us to analyze the improvements achieved by using forecasted precipitation fields separately from the accuracy of the rainfall-runoff model. However, in order to derive reliable results it was also necessary to obtain a good set of parameters for DiCHiTop by calibrating the model to typical rainfall runoff events on the studied basin. This ensured a good performance of the model, producing reliable estimated hydrographs, comparable to measured flows [for the implemented model, this was analyzed in detail in the study of Corral (2004)].

This paper is organized as follows: Section 2 gives a brief review of the implemented nowcasting technique. The environment of study, the rainfall-runoff model, and analyzed events are presented in section 3. Section 4 shows the results of the implementation, which are extended in section 5 and finally discussed in section 6 .

\section{The nowcasting technique}

The implemented technique for rainfall short-term forecasting is based on S-PROG [see a detailed description in Seed (2003)], and although there are slight differences compared to the original, we will use this name hereafter. S-PROG is a simple extrapolation technique that assumes steady-state conditions (see a general scheme in Fig. 1), in the sense that the most recently measured precipitation field is advected according to an 

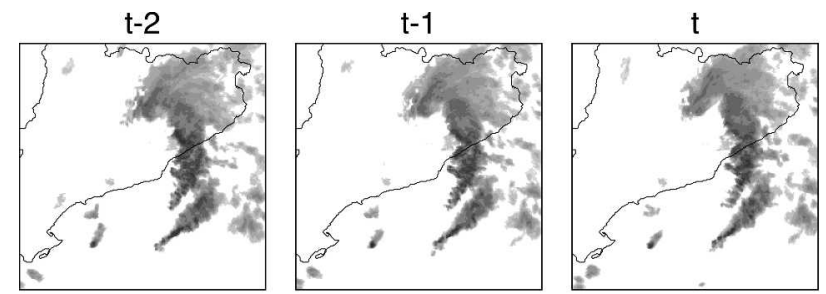

\section{OBSERVED}

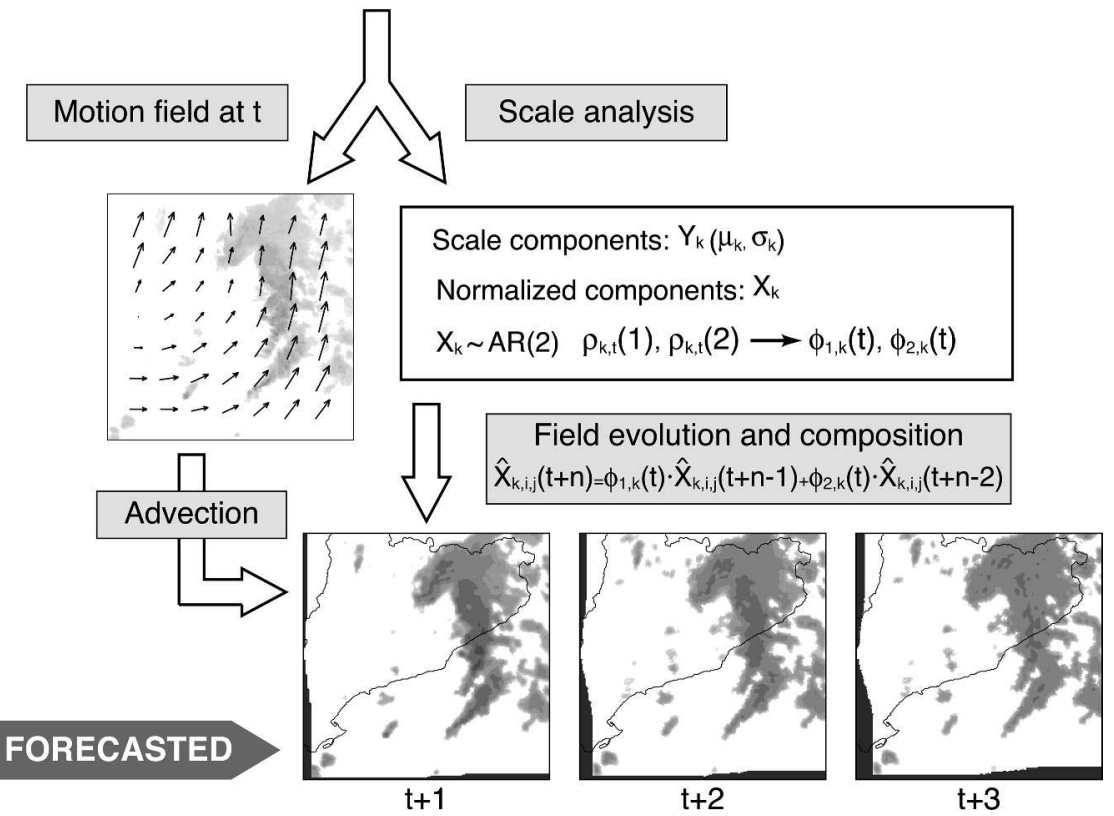

FIG. 1. General scheme of the implemented rainfall field nowcasting technique. From most recent observations at time $t$, the motion field and coefficients of the AR(2) models that drive the evolution of each range of scales are derived. The forecast at $t+n$ is obtained as the composition of the fields $\hat{X}_{k}(t+n)$, which are advected according to the motion field derived at $t$.

estimation of the current motion field of the precipitation.

Additionally, S-PROG proposes to filter out the small-scale patterns of the rainfall field as the forecasting time increases (see an example of the forecast in Fig. 2), because the temporal evolution of the small scale patterns of the precipitation field have been demonstrated to be very unpredictable using an extrapolation technique (Germann and Zawadzki 2002).

\section{a. Tracking algorithm}

The algorithm implemented to estimate the motion field of precipitation is based on tracking radar echoes by correlation (TREC; Rinehart and Garvey 1978) to which continuity is imposed [in the way proposed by $\mathrm{Li}$ et al. (1995)]. The motion field is obtained with a given resolution (in this case, $16 \mathrm{~km}$; see Fig. 3), and it is finally densified to the pixel resolution using linear interpolation.

\section{b. Spectral decomposition}

Each observed reflectivity field $Z(t)$ (expressed in $\mathrm{dB} Z$ ) is decomposed into a set of $m$ field components $Y_{k}(t)$ representing the variability of the precipitation in a range of scales $2^{k}$ to $2^{k+1}(\mathrm{~km})$, where $k \in[1, m]$, assuming a multifractal structure of precipitation fields that allows modeling them as a multiplicative cascade [an extensive review and discussion of this hypothesis may be found in Seed (2003)]. This decomposition is carried out using different bandpass filters in the Fourier spectrum (see Fig. 4).

After normalizing these field components, $Y_{k}(t)$, according to Eq. (1), an $\mathrm{AR}(2)$ model is fitted to the temporal series of each $X_{k}(t)$ using Eq. (2):

$$
\begin{aligned}
X_{k, i, j}(t)= & \frac{Y_{k, i, j}(t)-\mu_{k}(t)}{\sigma_{k}(t)}, \\
X_{k, i, j}(t)= & \phi_{1, k}(t) X_{k, i, j}(t-1)+\phi_{2, k}(t) X_{k, i, j}(t-2) \\
& +\varepsilon_{k, i, j}(t)
\end{aligned}
$$



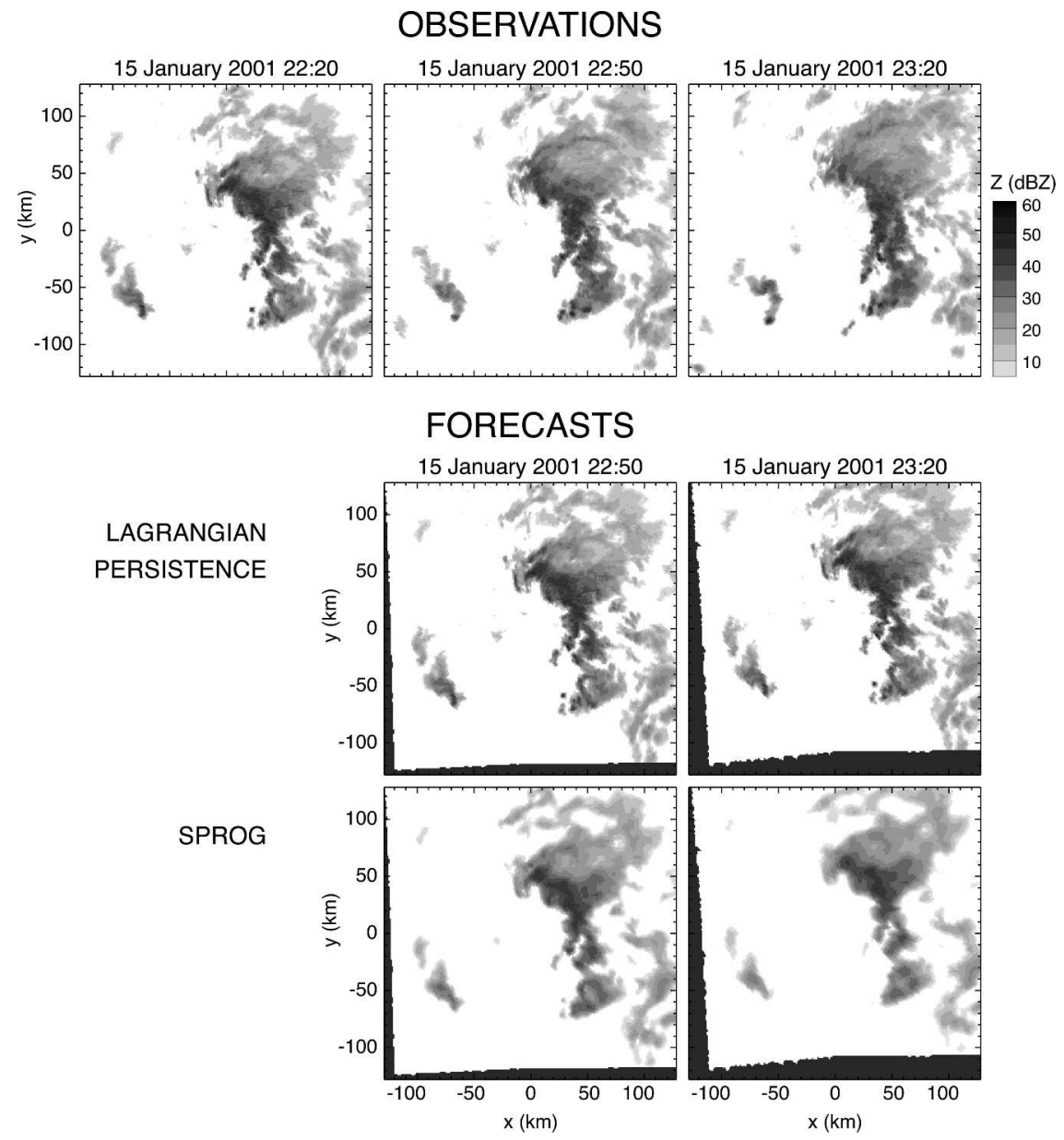

FIG. 2. (top) Radar reflectivity fields, measured at 2001, 2220, 2250, and 2320 UTC 15 Jan 2001; (middle) 30- and 60-min forecasts generated at 2220 UTC 15 Jan 2001 by simple advection of radar fields (Lagrangian persistence); and (bottom) 30- and 60-min forecasts generated at 2220 UTC 15 Jan 2001 by S-PROG (adding scale filtering to Lagrangian persistence).

where $i$ and $j$ stand for the pixel position, $\mu_{k}(t)$ and $\sigma_{k}(t)$ are the mean and standard deviation of the field component $Y_{k}(t)$, the coefficients $\phi_{1, k}(t)$ and $\phi_{2, k}(t)$ are obtained with the Yule-Walker equations as a function of the lag-1 and lag-2 autocorrelation coefficients, and $\varepsilon_{k, i, j}(t)$ is a white-noise process.

\section{c. Forecasting}

Since the temporal evolution of each level is modeled according to an $\operatorname{AR}(2)$ model, the lag- $n$ forecast of the normalized field component, $\hat{X}_{k}(t+n)$, can be generated recursively according to the model given in Eq. (3) (where the noise term, $\varepsilon$, is set to 0 to produce the expected "best" forecast):

$$
\begin{aligned}
\hat{X}_{k, i, j}(t+n)= & \phi_{1, k}(t) \hat{X}_{k, i, j}(t+n-1) \\
& +\phi_{2, k}(t) \hat{X}_{k, i, j}(t+n-2) .
\end{aligned}
$$

The $\hat{Z}(t+n)$ fields are finally recomposed by means of Eq. (4):

$$
\hat{Z}_{i, j}(t+n)=\sum_{k=1}^{m} \mu_{k}(t)+\sigma_{k}(t) \hat{X}_{k, i, j}(t+n) .
$$

Since smallest scales are less autocorrelated, forecasted fields representing small-scale variability will quickly tend to the $k$-component field mean, $\mu_{k}(t)$. Therefore, recomposed fields get smoother as the forecasting time increases, while the larger-scale characteristics persist relatively longer (see Fig. 2).

The recomposition of the reflectivity field $\hat{Z}(t+n)$ is done in the Lagrangian domain, which means that this field is advected according to the estimated motion field derived at $t$ with the mentioned TREC technique. The motion field is kept stationary during the forecasting time, and it is implemented according to a backward 


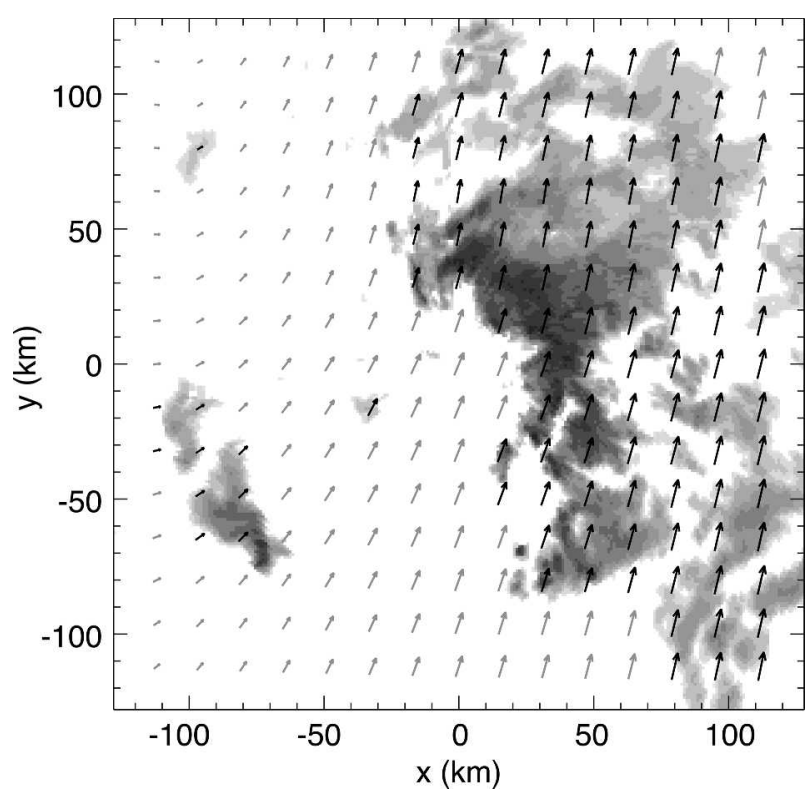

FIG. 3. Example of the precipitation motion field obtained by the tracking algorithm at 2220 UTC 15 Jan 2001.

scheme (see Fig. 8 of Germann and Zawadzki 2002). The advected reflectivity is thus obtained from the velocity vector estimated at each point $(i, j), \mathbf{v}(t)=\left[u_{t, i j}\right.$, $\left.v_{t, i j}\right]$, according to

$$
\hat{Z}_{i, j}(t+n)=\hat{Z}_{i-\Delta i, j-\Delta j}(t+n-1),
$$

where $\Delta_{i}=u_{t, i j} \Delta t, \Delta_{j}=v_{t, i j} \Delta t$, and $\Delta t$ is the time step.

\section{Implementation framework}

The implementation of S-PROG was carried out in the vicinity of Barcelona (see Fig. 5). This region has a typical Mediterranean climate: it is affected by intense rainfall events that frequently lead to important floods. In this area, at the end of summer, mountain ranges near the coast act as natural barriers causing the updraft of warm wet air from the sea, and this encourages the generation of local intense convective storms. However, stratiform systems (with high spatial and temporal extensions) are also common, especially in winter and spring.

The validation was carried out with six selected rainfall events corresponding both to convective and stratiform situations (some details are presented in Table 1). To analyze possible scale effects, results were derived in a set of five different-sized domains (presented in Fig. 6). The first one is the $256 \mathrm{~km} \times 256 \mathrm{~km}$ square centered at the radar site and the rest correspond to the Llobregat basin $\left(5040 \mathrm{~km}^{2}\right)$, the Besòs basin (1015 $\left.\mathrm{km}^{2}\right)$, and two of its subbasins [Mogent $\left(180 \mathrm{~km}^{2}\right)$ and Ripoll $\left.\left(65 \mathrm{~km}^{2}\right)\right]$.

On the other hand, hydrological validation has been carried out in the framework of the Besòs basin and its

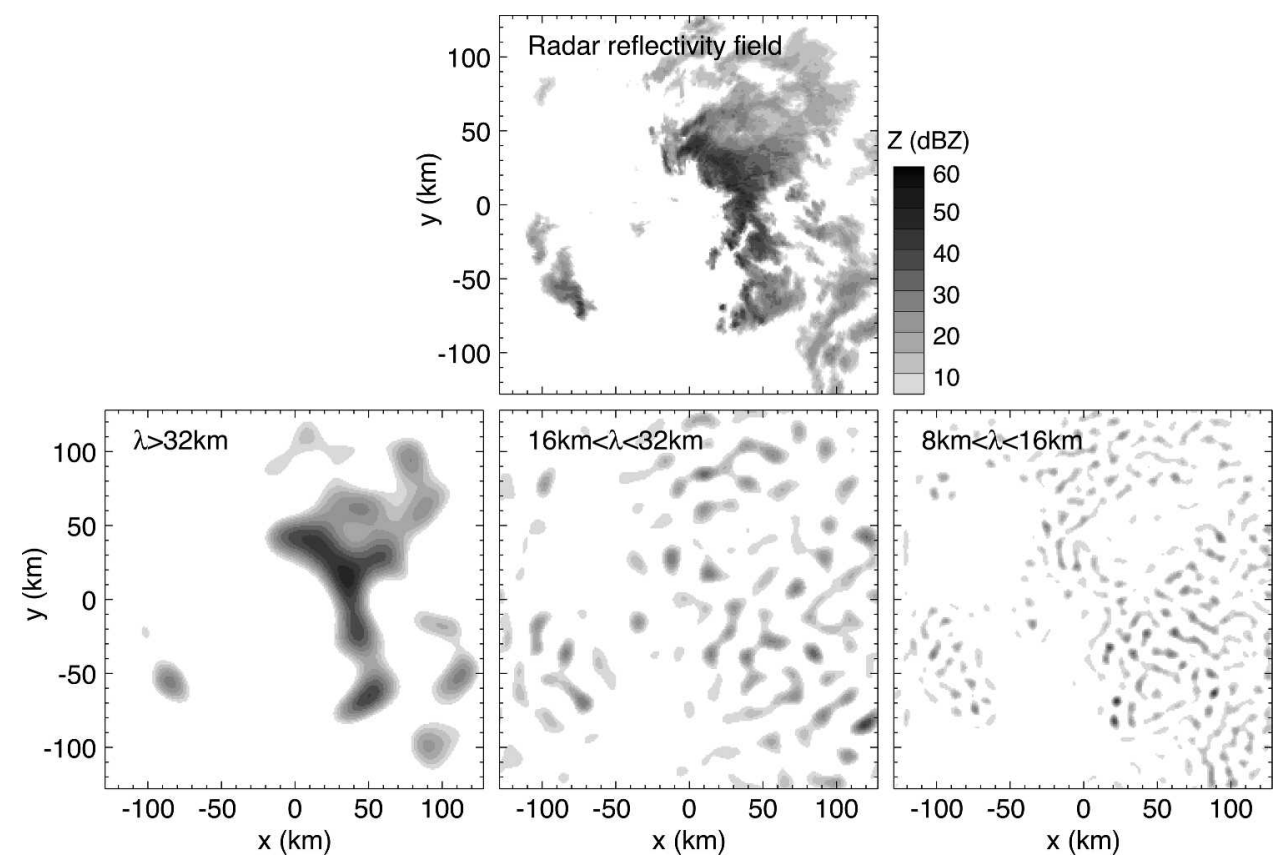

FIG. 4. (top) Original reflectivity field, $Z$, measured by the radar at 2220 UTC 15 Jan 2001. (bottom) Spectral decomposition of the radar field in components, $Y_{k}$, representing the variability of the field associated to scales (left) over $32 \mathrm{~km}$, (center) between 16 and $32 \mathrm{~km}$, and (right) between 8 and $16 \mathrm{~km}$. 

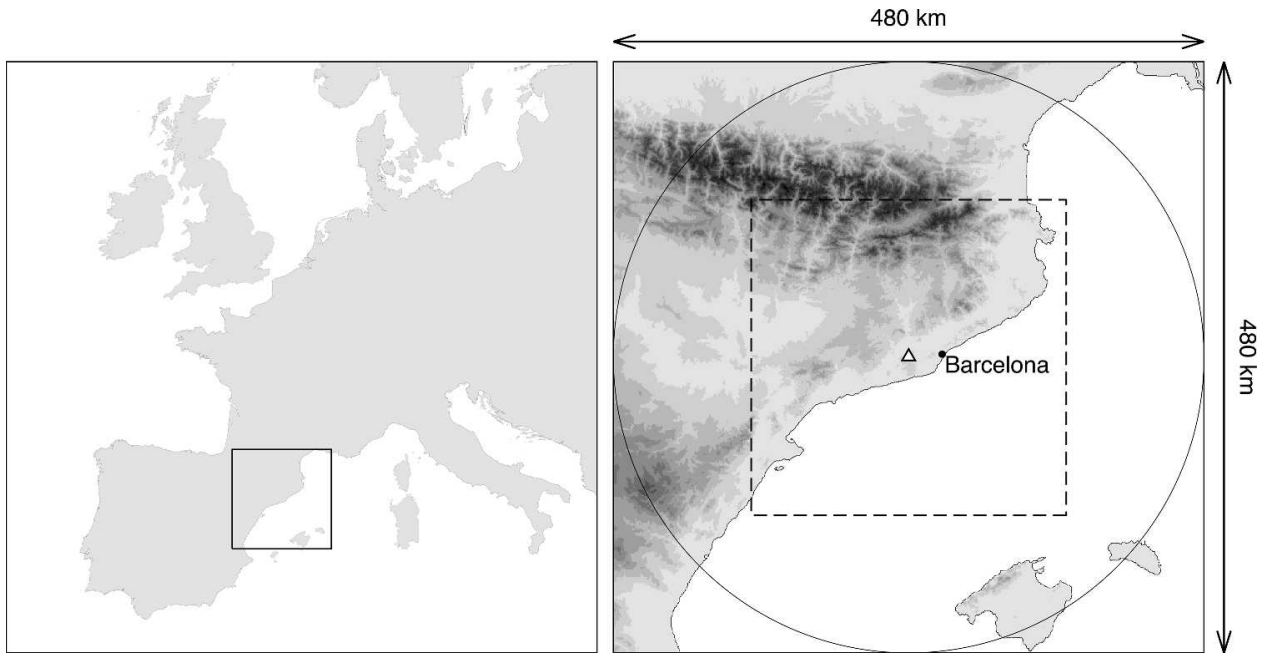

FIG. 5. Location of the studied area. (right) Triangle indicates the location of the Corbera C-band radar. The circumference shows the radar maximum range $(240 \mathrm{~km})$, and the dashed-line square is the $256 \times 256 \mathrm{~km}^{2}$ domain where the validation was carried out (see Fig. 6).

subbasins in four of the selected events (for which significant flows were measured in this basin; Table 1 also reports some details of the measured discharges). This is a typical example of a Mediterranean complex catchment: the upper part (with some mountains above 1000 $\mathrm{m}$ ) is mainly rural and forested, while the planes have suffered a continuous urbanization process during the last decades (the area close to the outlet is very densely populated). This basin is quite well instrumented, with seven level sensors (only three of them-defining the analyzed basins - are used in this study), and well covered by the radar (the furthest point of the basin is around $60 \mathrm{~km}$ to the radar). The events used for hydrological validation produced the most significant discharges between January 2000 and December 2002.
Peak flows measured during these events in the Besòs basin were close to the value calculated for a return period $T=2 \mathrm{yr}, Q_{T=2}=90 \mathrm{~m}^{3} \mathrm{~s}^{-1}$ (as a reference, $Q_{T=5}$ $=190 \mathrm{~m}^{3} \mathrm{~s}^{-1}$ ). Therefore, none of the analyzed events can be considered extreme, and this could be a limitation to extend the conclusions of this study to severe events.

\section{a. Radar data}

Radar data were measured with the C-band radar of the Spanish Institute of Meteorology (INM) located at Corbera de Llobregat, near Barcelona (its technical characteristics are summarized in Table 2 and its location is shown in Fig. 5). Raw radar data were corrected for mountain screening effects [with the algorithm pro-

TABLE 1. Characteristics of the events selected for the validation of the tested forecasting techniques (see radar loops of these events online at http://www.grahi.upc.edu/events.php). Hydrological validation has been carried out over the events for which significant flows were measured at the outlet of the Besòs basin (shaded). In the table, "AMAR" stands for accumulated mean areal rainfall estimated from radar measurements, "Qmax" for measured peak flow, "C" for convective, and "S" for stratiform. Here (*) indicates that the level sensor did not work properly. Start and end times are in UTC.

\begin{tabular}{|c|c|c|c|c|c|c|c|c|c|c|}
\hline \multirow{2}{*}{\multicolumn{3}{|c|}{$\begin{array}{c}\text { Rainfall analysis } \\
\text { Radar domain } \\
(256 \mathrm{~km} \times 256 \mathrm{~km})\end{array}$}} & \multicolumn{7}{|c|}{ Flow analysis } & \multirow{3}{*}{$\begin{array}{l}\text { Na- } \\
\text { ture } \\
\text { of the } \\
\text { event }\end{array}$} \\
\hline & & & \multirow{2}{*}{$\begin{array}{l}\text { Dura- } \\
\text { tion } \\
\text { (h) }\end{array}$} & \multicolumn{2}{|c|}{$\begin{array}{l}\text { Besòs basin } \\
\left(1015 \mathrm{~km}^{2}\right)\end{array}$} & \multicolumn{2}{|c|}{$\begin{array}{l}\text { Mogent basin } \\
\quad\left(180 \mathrm{~km}^{2}\right)\end{array}$} & \multicolumn{2}{|c|}{$\begin{array}{l}\text { Ripoll basin } \\
\left(65 \mathrm{~km}^{2}\right)\end{array}$} & \\
\hline Start & End & $\begin{array}{c}\text { AMAR } \\
(\mathrm{mm})\end{array}$ & & $\begin{array}{c}\text { AMAR } \\
(\mathrm{mm})\end{array}$ & $\begin{array}{c}\text { Qmax } \\
\left(\mathrm{m}^{3} \mathrm{~s}^{-1}\right)\end{array}$ & $\begin{array}{c}\text { AMAR } \\
(\mathrm{mm})\end{array}$ & $\underset{\left(\mathrm{m}^{3} \mathrm{~s}^{-1}\right)}{\mathrm{Qmax}}$ & $\begin{array}{c}\text { AMAR } \\
(\mathrm{mm})\end{array}$ & $\begin{array}{c}\mathrm{Qmax} \\
\left(\mathrm{m}^{3} \mathrm{~s}^{-1}\right)\end{array}$ & \\
\hline 1600 UTC 28 Sep 2000 & 0500 UTC 29 Sep 2000 & 8 & 72 & 8 & 35 & 11 & 1 & 8 & 2 & $\mathrm{C} / \mathrm{S}$ \\
\hline 2100 UTC 22 Dec 2000 & 1200 UTC 23 Dec 2000 & 5 & 102 & 30 & 88 & 28 & 4 & 31 & 6 & $\mathrm{C} / \mathrm{S}$ \\
\hline 0000 UTC 15 Jan 2001 & 2400 UTC 15 Jan 2001 & 4 & 48 & 38 & 103 & 45 & 21 & 49 & $(*)$ & $\mathrm{S}$ \\
\hline 0500 UTC 19 Jul 2001 & 1300 UTC 19 Jul 2001 & 5 & 36 & 14 & 78 & 13 & $(*)$ & 14 & $(*)$ & $\mathrm{C} / \mathrm{S}$ \\
\hline 2200 UTC 14 Nov 2001 & 0200 UTC 16 Nov 2001 & 13 & 42 & 51 & 92 & 55 & $(*)$ & 65 & $(*)$ & $\mathrm{S} / \mathrm{C}$ \\
\hline 2200 UTC 8 Oct 2002 & 1000 UTC 10 Oct 2002 & 24 & 80 & 58 & $(*)$ & 52 & 4 & 72 & $(*)$ & $\mathrm{C}$ \\
\hline
\end{tabular}




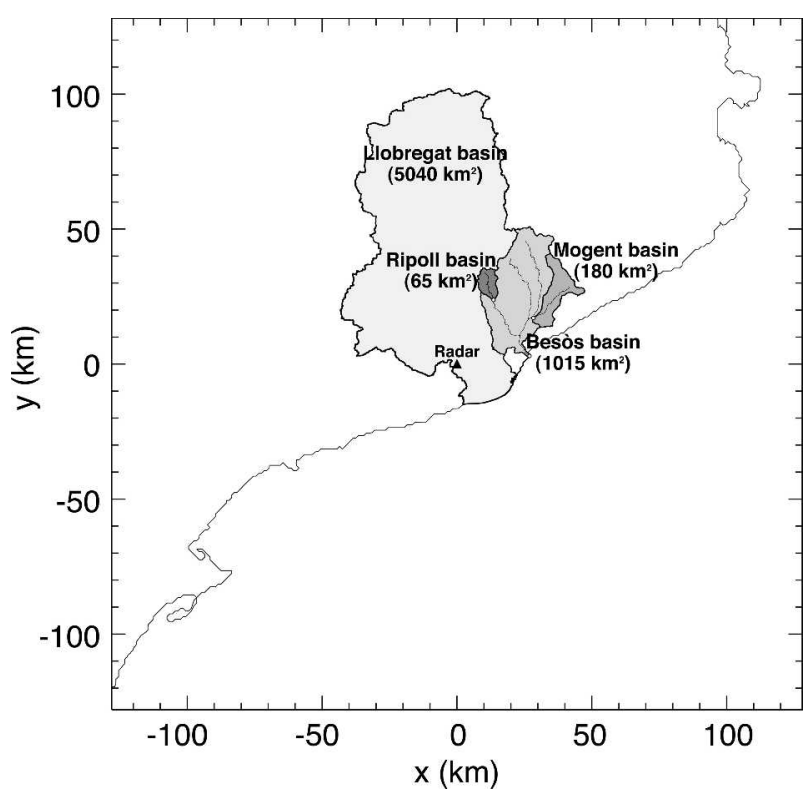

FIG. 6. Domains where the proposed nowcasting technique was validated: the quality of forecasted precipitation fields was assessed in the $256 \times 256 \mathrm{~km}^{2}$ area centered at radar location and in four different-sized catchments: Llobregat $\left(5040 \mathrm{~km}^{2}\right)$, Besòs $\left(1015 \mathrm{~km}^{2}\right)$, Mogent $\left(180 \mathrm{~km}^{2}\right)$, and Ripoll $\left(65 \mathrm{~km}^{2}\right)$. Hydrological validation was only carried out in Besòs, Mogent, and Ripoll basins.

posed by Delrieu and Creutin (1995)], ground clutter contamination [the technique proposed by SánchezDiezma et al. (2001b) was used both for identification of ground echoes and rainfall estimation], and problems of signal stability [with the technique described by Sempere-Torres et al. (2003)].

\section{b. The rainfall-runoff model}

DiCHiTop [see a more complete description in Corral et al. (2001) and Corral (2004)] is a grid-based model able to use distributed rainfall fields (provided by a radar, e.g.). To implement the model, the basin has to

TABLE 2. Main characteristics of the C-band $\operatorname{radar}(\lambda=5.3 \mathrm{~cm})$ used in this study (located in Corbera de Llobregat, near Barcelona).

\begin{tabular}{lc}
\hline \hline Frequency & $5620 \mathrm{MHz}$ \\
PRF & $250 \mathrm{~Hz}$ \\
Pulse length & $2 \mu \mathrm{s}$ \\
Beamwidth $(3 \mathrm{~dB})$ & $0.9^{\circ}$ \\
Azimuthal resolution & $0.86^{\circ}$ \\
Peak power & $250 \mathrm{~kW}$ \\
Radial resolution & $2 \mathrm{~km}$ \\
Maximum range & $240 \mathrm{~km}$ \\
No. of elevations & 20 \\
Lowest elevation & $0.5^{\circ}$ \\
Height & $664 \mathrm{~m} \mathrm{MSL}$ \\
\hline
\end{tabular}

be split into square hydrological cells matching the radar information (in this case, with a resolution of $2 \times 2$ $\mathrm{km}^{2}$ ). At this cell scale, a lumped model is applied to transform precipitation inputs into flow. Depending on the degree of urbanization of each cell, the chosen lumped model in rural areas is TOPMODEL (Beven and Kirkby 1979) or the Soil Conservation Service (SCS) loss function (Mockus 1957; see Rawls et al. 1992) in urban cells.

The runoff generated at each cell is routed to the outlet of the basin according to a transfer function derived from the main drainage system, which classifies basin cells as hillslope or stream cells. In the hillslope path, the output from a cell is attenuated in its journey to the nearest stream, where a fully channeled flow is assumed. This response is thus modeled by applying the Nash unit hydrograph (Nash 1957) in the hillslope path and a time delay in the stream, which is dependent on the distance to the outlet. The hydrograph at the basin outlet is finally calculated as the linear combination of all transferred cell hydrographs (see a general scheme of the model in Fig. 7).

The five parameters of the distributed rainfall-runoff model DiCHiTop were calibrated for the Besòs basin

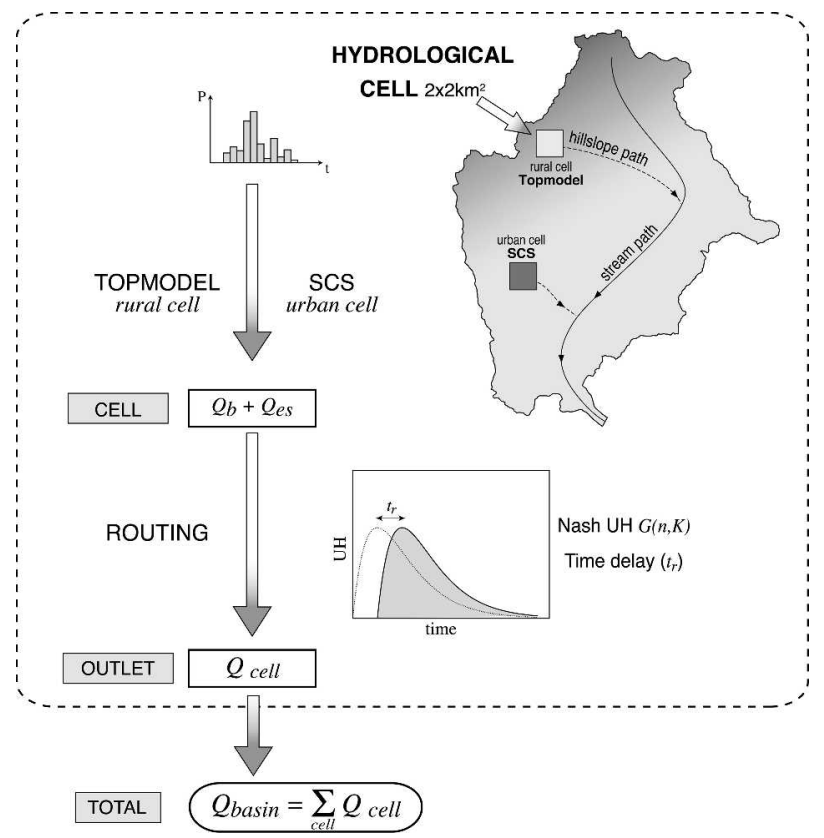

FIG. 7. Scheme of the distributed rainfall-runoff model DiCHiTop: the basin is divided into a grid of square hydrological cells matching the radar information. Depending on the degree of urbanization, different lumped models are applied to generate the runoff at cell scale. These cell flows are routed to the outlet of the basin independently by means of a Nash unit hydrograph derived from the drainage system. Finally, the basin hydrograph is calculated as the linear combination of all the routed cell hydrographs. 
by means of an optimization process minimizing the root-mean-square error (rmse) between simulated and observed hydrographs for a number of events. The model is currently running in real time as part of the Besòs Basin Warning System (SAHBE) using rain gauge-adjusted radar fields with a time step of $10 \mathrm{~min}$ [a full description and analysis of the performance of the model may be found in Corral (2004)].

\section{c. Validation schemes}

As mentioned above, the evaluation of the performance of the nowcasting technique was done from two different points of view: (a) in rainfall terms and (b) in terms of the flow simulated with the rainfall-runoff model.

\section{1) Forecasted PRECIPITATION FIELDS}

This comparison consisted of evaluating the error made in the forecasted precipitation fields. Results are presented in terms of the rmse as a function of the forecasting time (also called lead time) in units of rain rate, assuming a climatological $Z-R$ relationship for the studied area derived from disdrometer measurements (Sempere-Torres et al. 1997, 1998).

The performance of S-PROG was also compared against the results of Eulerian and of Lagrangian persistences. These three techniques represent progressive levels of sophistication: the difference between Eulerian and Lagrangian persistences is that advection of the rainfall field is introduced in the second (according to the motion field estimated with the TREC technique of section 2a); on the other hand, the difference between Lagrangian persistence and S-PROG is that SPROG filters out small-scale patterns of the rainfall field (see section 2).

This part of the study represents an extension of the 48-h case study analyzed by Seed (2003) using radar data from Melbourne (Australia), in the sense that the technique was here implemented for more events affecting a different region and evaluated in the five different-sized domains of Fig. 6.

\section{2) ForecAsted HYDROGRAPHS}

Hydrological validation consists of comparing the hydrographs simulated using a rainfall-runoff model fed with different sets of precipitation fields against a reference hydrograph in order to evaluate the effect of implementing different quality control or forecasting techniques. The essential idea is not just to measure the performance of the analyzed technique in terms of precipitation (sometimes this is done in a reduced number of points, e.g., rain gauges), but in terms of a spatially integrated variable: the runoff at the basin outlet (taking, thus, into account the impact of the analyzed algorithms at the hydrological scale).

As the main objective of the present study was to validate different rainfall nowcasting techniques from a hydrological point of view, it was therefore necessary to compare forecasted hydrographs against a reference hydrograph. As mentioned in section 1, we defined the reference hydrographs as the output flows simulated with the rainfall-runoff model at the outlet of the basin using as input the complete series of observed radar fields. In this study, they were assumed to be the reference, since the reference hydrographs are expected to be the best estimates of the actual discharges at the outlet.

On the other hand, forecasted hydrographs were obtained according to the analysis of the multiple-stepahead forecast (see, e.g., WMO 1992): They are built with the flow estimates forecasted using the model with an anticipation $\tau$ at each time step of the event, $t_{i}$ $(i=1, \ldots, p)$. At $t_{i}$, all available rainfall information (both the radar fields measured between $t_{1}$ and $t_{i}$ and the forecasts for $t_{i+1}, \ldots, t_{i}+\theta$, where $\theta$ is the duration of the rainfall forecast) is input to the rainfallrunoff model to produce the simulated hydrograph that would be available at $t_{i}$ in operational real-time conditions. Thus, hereafter, we will call them real-time hydrographs ( $p$ real-time hydrographs are generated during the event; see three examples in the upper part of Fig. 8 for different time steps). Finally, the forecasted hydrograph obtained with an anticipation $\tau$ is built from the set of the $p$ real-time hydrographs, as the sequence of the $p$ flow values $Q_{t_{i}}\left(t_{i}+\tau\right)$ forecasted at each time step $t_{i}$ for $t_{i}+\tau(i=1, \ldots, p)$, as shown in Fig. 8.

This way of generating forecasted hydrographs allows us to assess the reliability of runoff estimates simulated for $\tau$ hours ahead. Moreover, this methodology was chosen as an option close to operational conditions of real-time flow-forecasting systems. In this framework, operational warnings are usually given when the flow is foreseen to exceed a fixed threshold [e.g., when the low-level river bed is expected to be totally full; see Corral et al. (2002)]. However, forecasted hydrographs may not be considered as "real hydrographs" because they are not only generated with a run of the rainfallrunoff model, but with the flow estimates simulated at different time steps, from the set of real-time hydrographs of the event.

It is worth noting that other studies chose different alternative procedures to evaluate simulated hydrographs. For instance, Dolcine et al. (2001) generated 


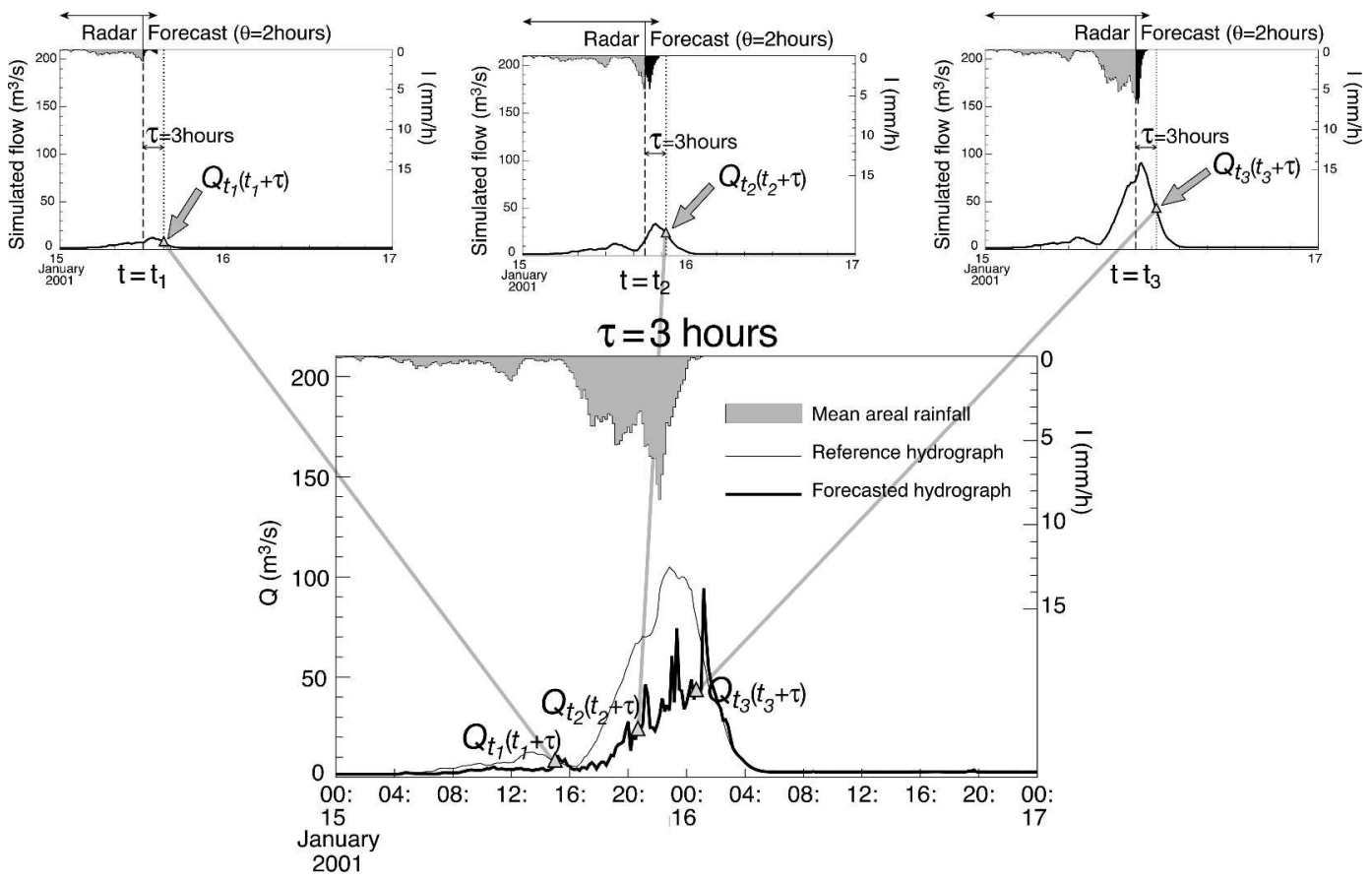

FIG. 8. Scheme of the generation of the hydrographs forecasted with an anticipation $\tau(\tau=3 \mathrm{~h}$ in the example). The three upper figures are real-time hydrographs calculated with the rainfall-runoff model in three different time steps of the event, $t_{i}$ (marked with dashed lines). Precipitation inputs are made of past radar scans plus $\theta=2 \mathrm{~h}$ of forecasted rainfall fields. Hydrographs forecasted with an anticipation $\tau$ (bottom, thick line) are constructed taking at any time step, $t_{i}$, the flow estimates simulated with the rainfall-runoff model for $t_{i}+\tau, Q_{t i}\left(t_{i}+\tau\right)$. Forecasted hydrographs are finally compared against the reference hydrograph, which is calculated by the model using the complete sequence of radar scans (bottom, thick line).

output hydrographs with a single run of the rainfallrunoff model, using as input the whole series of precipitation fields forecasted with some anticipation. On the other hand, Mecklenburg et al. (2001) focused on the analysis of real-time hydrographs, which is more similar to the proposed study. However, the analysis of the multiple-step-ahead forecast is thought to be a better way to group and synthesize forecasted flow estimates.

Finally, the statistic used to evaluate the quality of forecasted flows is the multiple-step-ahead forecast efficiency index, $\operatorname{eff}(\tau)$ : the forecasted hydrographs, $Q_{t_{i}-\tau}\left(t_{i}\right)$, were compared against the reference hydrograph, $Q_{\text {ref }}\left(t_{i}\right)$, in terms of the Nash efficiency (Nash and Sutcliffe 1970) expressed as a function of the anticipation with which the flow estimates were forecasted, $\tau$ [see Eq. (6), where $\overline{Q_{\text {ref }}}$ is the mean flow value of the reference hydrograph]:

$$
\operatorname{eff}(\tau)=1-\frac{\sum_{t_{i}=t_{1}+\tau}^{t_{p}}\left[Q_{\mathrm{ref}}\left(t_{i}\right)-Q_{t_{i}-\tau}\left(t_{i}\right)\right]^{2}}{\sum_{t_{i}=t_{1}+\tau}^{t_{p}}\left[Q_{\mathrm{ref}}\left(t_{i}\right)-\overline{Q_{\mathrm{ref}}}\right]^{2}} .
$$

\section{Results}

\section{a. Evaluation of forecasted rainfall fields}

Figure 9 shows the results of comparing precipitation forecasts against actually measured radar fields expressed in terms of the rmse (in millimeters per hour). In the entire analyzed domain $\left(256 \times 256 \mathrm{~km}^{2}\right.$; see Fig. 6 ) and for all studied cases, Lagrangian persistence produces better results than Eulerian persistence. Moreover, the introduction of scale filtering (S-PROG) yielded significantly better results.

Figure 10 shows the effect of basin size in the rmse of the forecasted rainfall fields for three of the analyzed events (similar results were obtained for the other three cases). In general, S-PROG produced better forecasts than other algorithms, independently of the analyzed domain. However, results seem to be, at basin scale, more sensitive to the nonstationarity of the motion field imposed in the forecast (or to a not-good-enough motion estimation). This may be the cause of some bad results obtained with Lagrangian persistence in comparison to Fig. 9, (this was partially sorted out by S-PROG, thanks to the smoothing effect of scale filtering). 

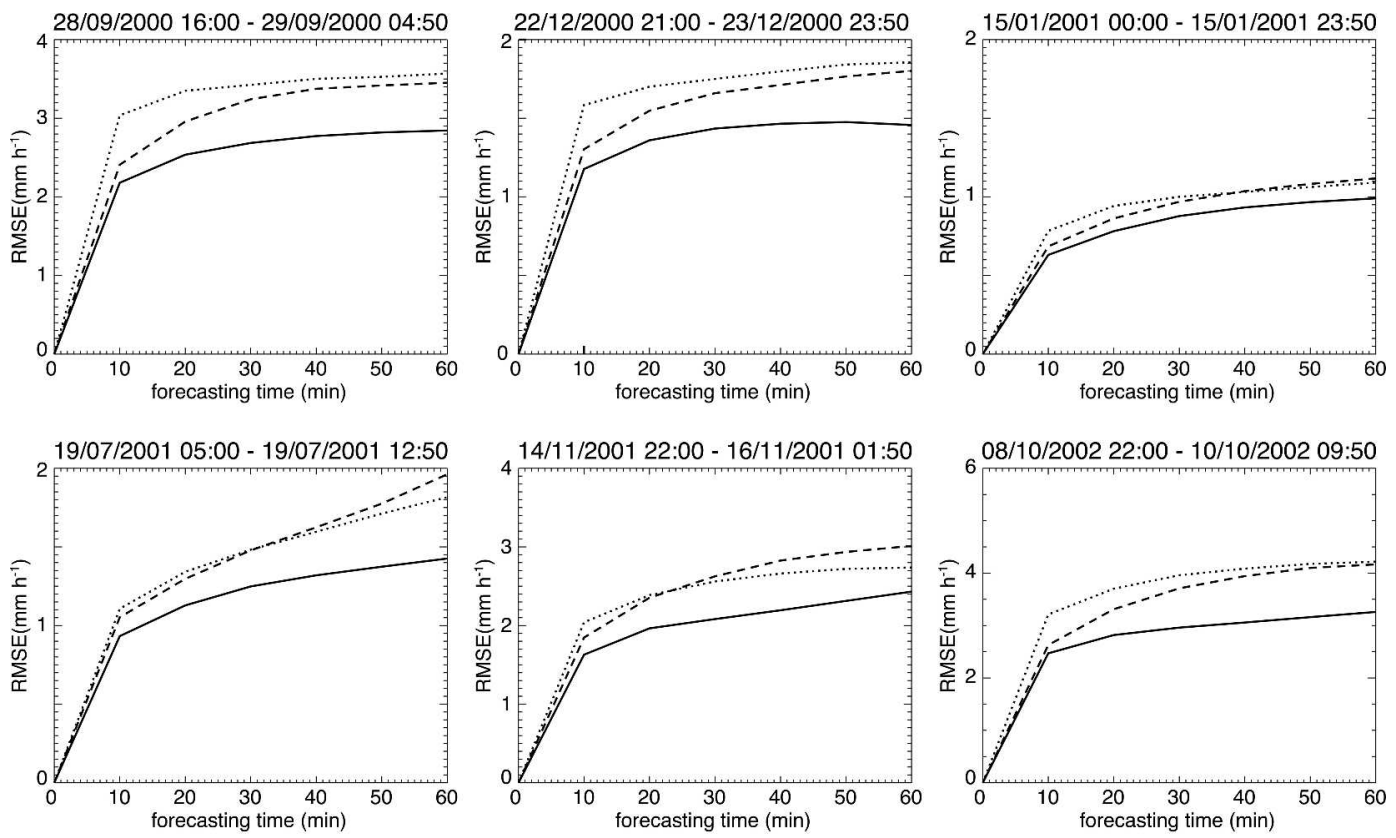

$$
\text { .............. Eulerian persistence -.-.-.- Lagrangian persistence _ S-PROG }
$$

FIG. 9. Rmse (in $\mathrm{mm} \mathrm{h}^{-1}$ ) evaluated in the $256 \times 256 \mathrm{~km}^{2}$ domain of Fig. 10 as a function of the forecasting time for chosen events. Three lines distinguish between forecasting techniques: dotted line corresponds to Eulerian persistence (last radar scan is kept static as forecast), dashed line corresponds to Lagrangian persistence (advection of last radar scan according to the estimated motion field), and solid line corresponds to S-PROG.

\section{b. Evaluation of forecasted hydrographs}

Figure 11 shows the evolution of the efficiency of forecasted hydrographs (compared to the reference hydrograph) with the anticipation of flow forecasting, $\tau$, for the four analyzed events. In this case, the results of using rainfall forecasts obtained with Lagrangian persistence (dashed line) and S-PROG (solid line) are compared against the results of considering no precipitation forecast as input of the rainfall-runoff model (dotted line).

In all cases, the inclusion of a nowcasting technique based on radar scans (Lagrangian persistence or SPROG) significantly improved the quality of the forecasted hydrographs. However, the hydrographs simulated with precipitation fields forecasted using S-PROG were not better than those obtained using rainfall fields derived by simple advection of the last radar scan. This result may be explained by two factors: (a) because the average rainfall rate of S-PROG over the radar domain tends to decrease with the forecasting time as the advected field gets smoothed, while the Lagrangian forecasted field average keeps constant, and (b) because hydrological basins tend to integrate and filter out precipitation patterns, making the filtering capacity of SPROG useless compared to Lagrangian persistence (an additional filter of small-scale patterns is not worthwhile).

Taking into account that in general terms a simulated hydrograph obtaining a Nash efficiency of 0.90 may be considered as a good match to the reference hydrograph, the anticipation for which this efficiency is obtained, $\tau_{0.90}$, can provide an idea of the anticipation with which simulated flows could be accurately forecasted. For instance, without any rainfall forecast, for the case of 22 December 2000 in the Besòs basin, $\tau_{0.90}$ was around $100 \mathrm{~min}$ (as indicated with an arrow in the top-left graph of Fig. 11). This may be considered as a first approximation of the lag time of this basin (approximately, the time elapsed between the rainfall input and the main response of the basin), which may be estimated between 90 and $120 \mathrm{~min}$, depending on the event.

In the Besòs basin, the results show that $\tau_{0.90}$ could be extended further between 10 and 80 min when a nowcasting algorithm based on radar scans was implemented. It is also shown that $\tau_{0.90}$ clearly depends on the nature of the rainfall event (stratiform or convective) and on the precipitation distribution over the basin. For example, it is worth noting that the worst results for all basins were obtained for the event of 15 

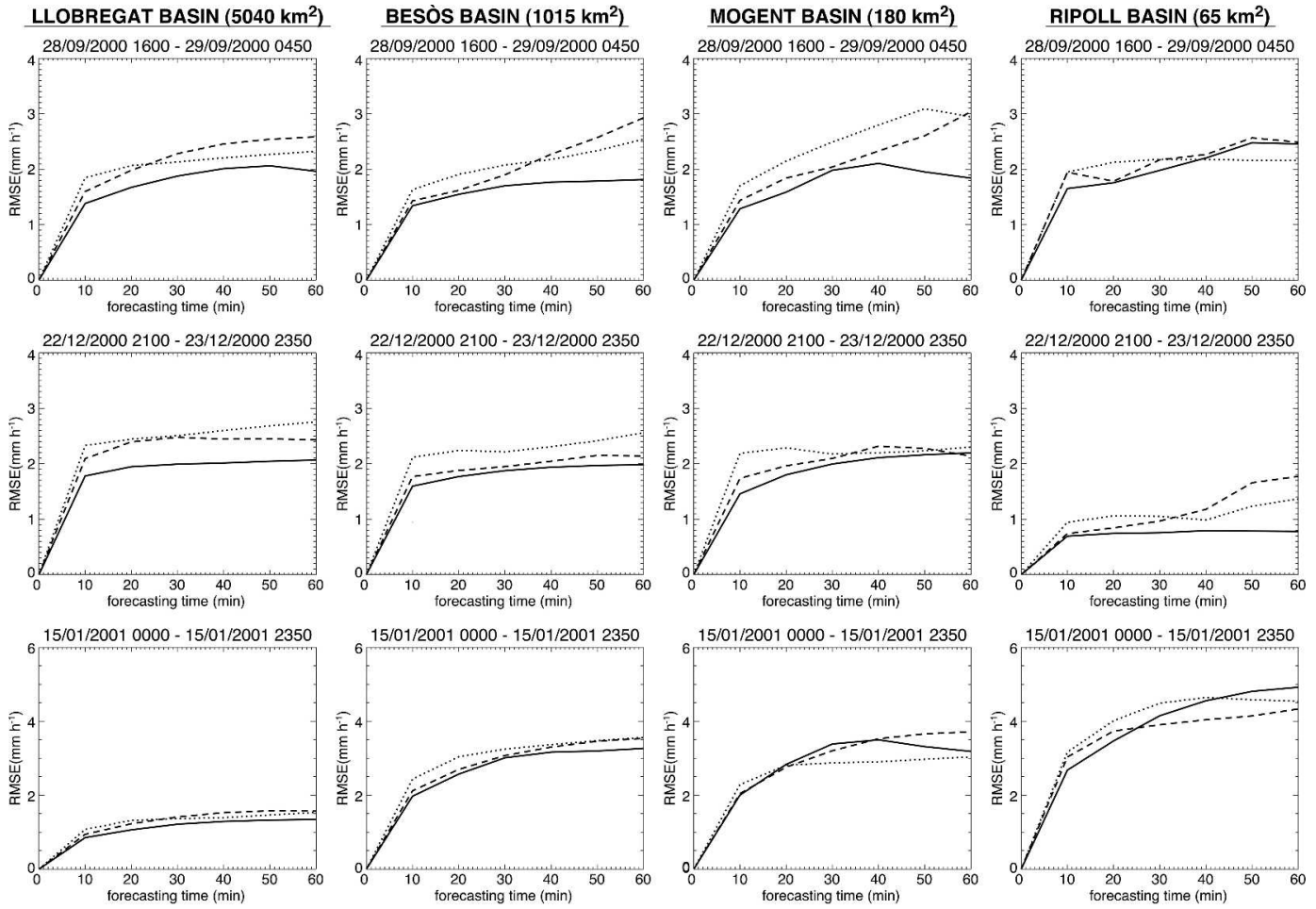

Eulerian persistence ---.-.. Lagrangian persistence _ S-PROG

FIG. 10. Same as in Fig. 9 but for three events and for the different-sized basins shown in Fig. 6.

November 2001. In this case, the use of a short-term forecasting technique hardly allowed us to extend the anticipation with which flows could be forecasted accurately $\left(\tau_{0.90}\right.$ is not increased by more than 10 min using a forecasting technique). During this event, both stratiform and convective periods affected the studied area; very influential cells were rapidly enhanced by mountain chains close to the coast and quickly moved over the studied basins, producing high rainfall intensities. Therefore, the poor results can be explained by the limitations of the analyzed nowcasting techniques, which can take into account neither the role of the orography nor the generation and evolution of shortduration convective cells. On the other hand, for the event of 19 July 2001, the obtained results were very good. Although the first part of this event could be considered as mainly convective, it had a long stratiform second period that significantly affected the studied domain. Moreover, the convective systems were quite large, well organized, and had long lifetimes. Their evolution, was, therefore, more predictable than the evolution of the small storm cells of the 15 November 2001 case (as justified in Wilson et al. 1998). Furthermore, the field advection remained reasonably stationary during the different parts of the event. All these factors allowed $\tau_{0.90}$ to be extended for $80 \mathrm{~min}$ (up to $150 \mathrm{~min}$ ) in the Besòs basin when using Lagrangian persistence and S-PROG.

In the small basins, $\tau_{0.90}$ was shorter than in the Besòs basin, but it could also be usefully extended: in the Mogent basin the improvement was significant, between 10 and 70 min (similar to the results obtained in the Besòs), and in the Ripoll basin the extension was between 10 and $40 \mathrm{~min}$.

From the analysis of real-time hydrographs in operational conditions it was noted that bad estimations of the motion field could have significant negative effects in the simulated hydrographs. On the other hand, a good estimation of the average rainfall over the basin seems to be the key factor in improving forecasted hydrographs (especially in the case of small basins). Finally, it should be underlined that in this part of the study the duration of rainfall forecasts was set to $\theta=2 \mathrm{~h}$ (this duration was adopted as a compromise between using shorter series, which could limit the quality of hydrographs simulated by the model, and using longer forecasts, which have increasingly poor quality). The importance of these three factors in resulting flow simulations is evaluated in the next section. 
BESÒS BASIN $\left(1015 \mathrm{~km}^{2}\right)$
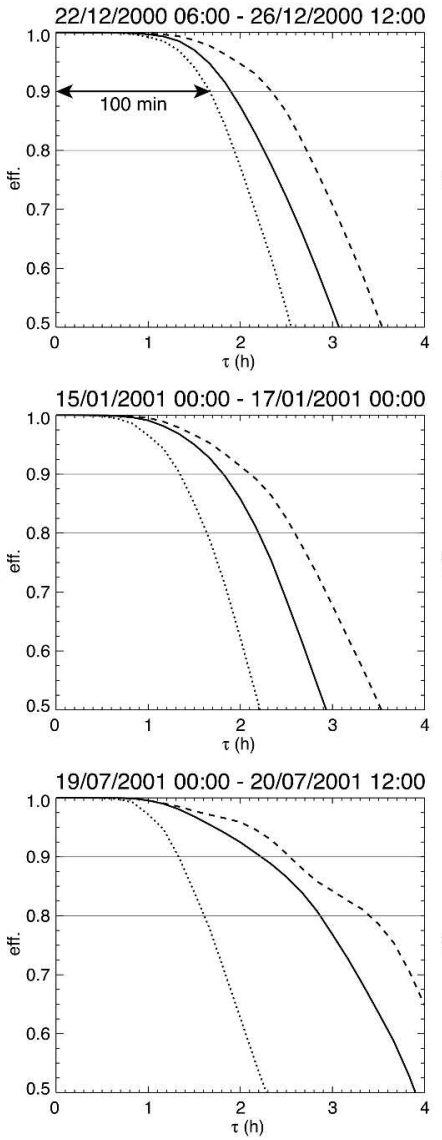

15/11/2001 06:00 - 17/11/2001 00:00

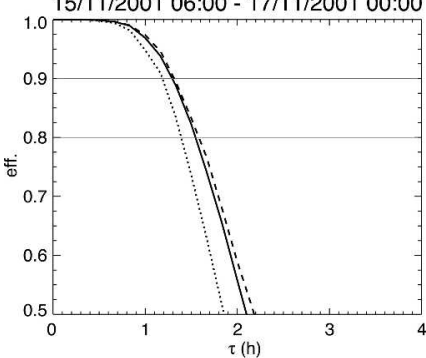

MOGENT BASIN $\left(180 \mathrm{~km}^{2}\right)$
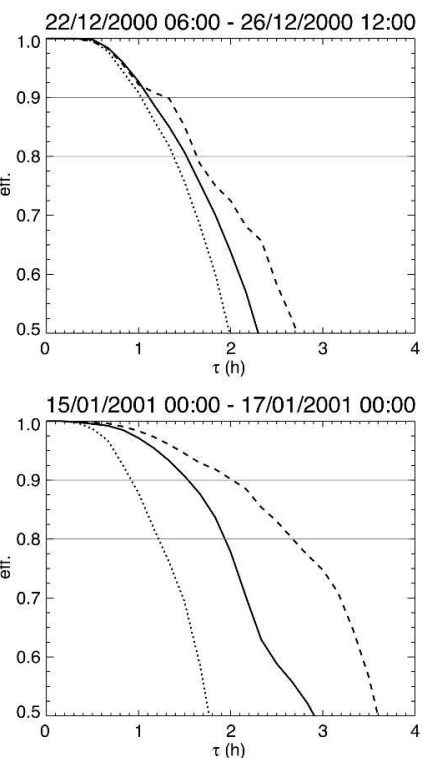

19/07/200100:00 - $20 / 07 / 200112: 00$

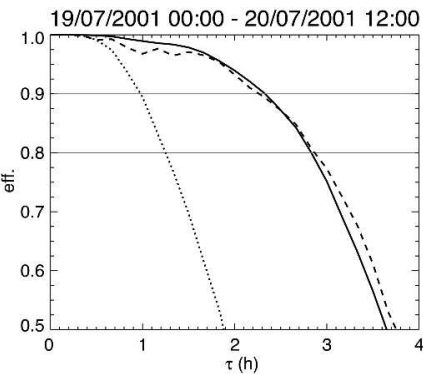

15/11/2001 06:00 - 17/11/200100:00

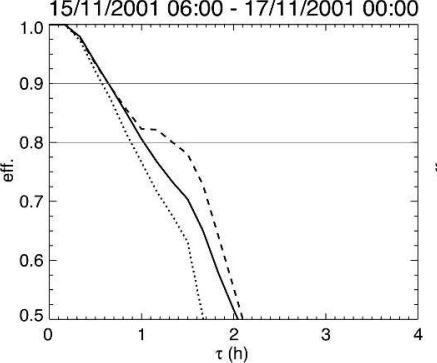

RIPOLL BASIN $\left(65 \mathrm{~km}^{2}\right)$
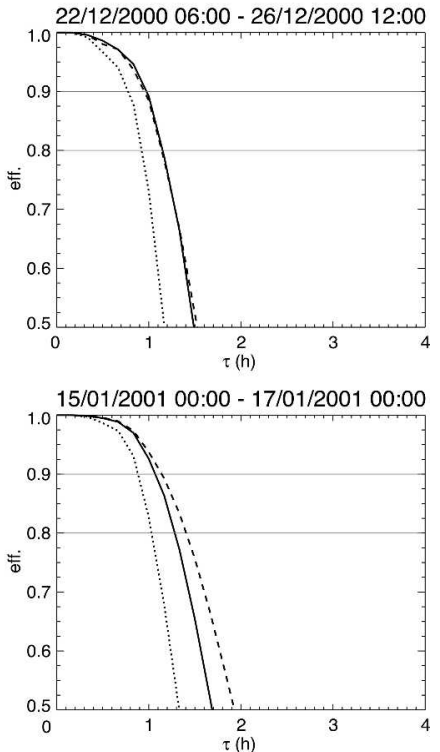

(19/07/2001 00:00 - 20/07/2001/12:00

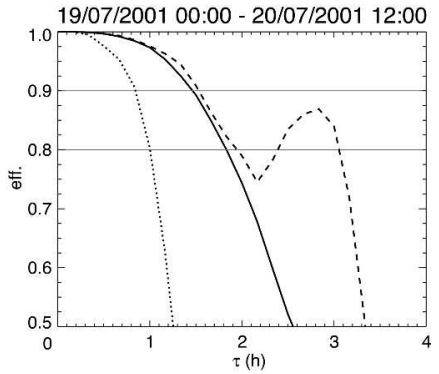

$15 / 11 / 200106: 00-17 / 11 / 200100: 00$

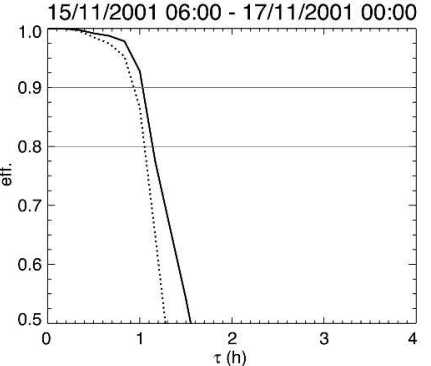

No forecast

Lagrangian persistence

S-PROG

FIG. 11. Evolution of the Nash efficiency of the forecasted hydrographs as a function of the anticipation with which hydrographs are simulated, $\tau$. Different lines represent hydrographs simulated with precipitation fields forecasted with different techniques: with no forecast (dotted line), Lagrangian persistence (dashed line), and S-PROG (solid line).

\section{Factors affecting the quality of forecasted hydrographs}

An analysis of important factors that could affect the accuracy of forecasted hydrographs is carried out in this section. Particularly, three factors are analyzed: (a) the duration of the rainfall forecasts input to the rainfallrunoff model, (b) the impact of advecting the most recent precipitation field with a stationary motion to generate rainfall forecasts (as assumed both by Lagrangian persistence and S-PROG), and (c) the importance of a good forecast of the mean areal rainfall. 
BESÒS BASIN $\left(1015 \mathrm{~km}^{2}\right)$
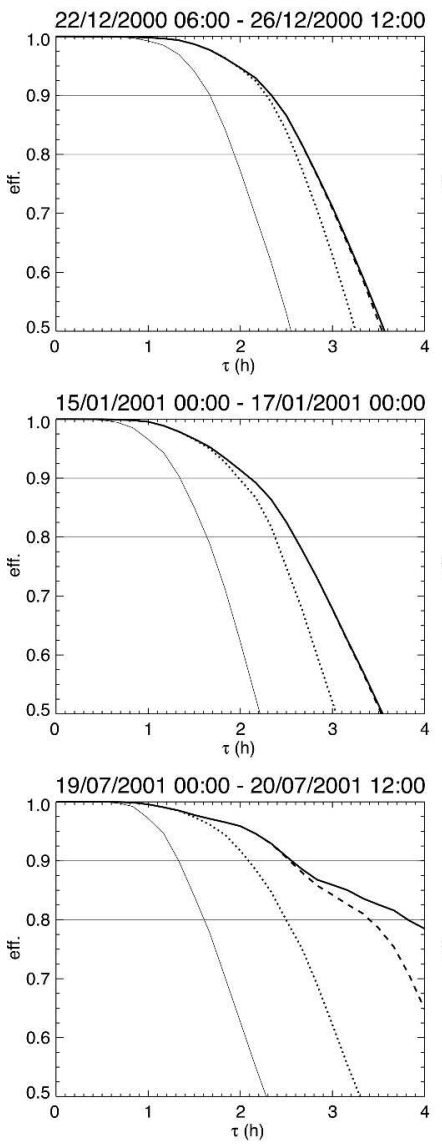

15/11/2001 06:00 - 17/11/200100:00

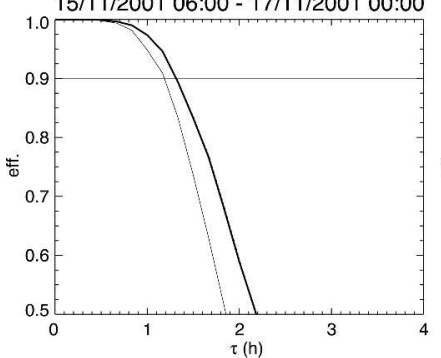

MOGENT BASIN $\left(180 \mathrm{~km}^{2}\right)$

22/12/2000 06:00 - 26/12/2000 12:00
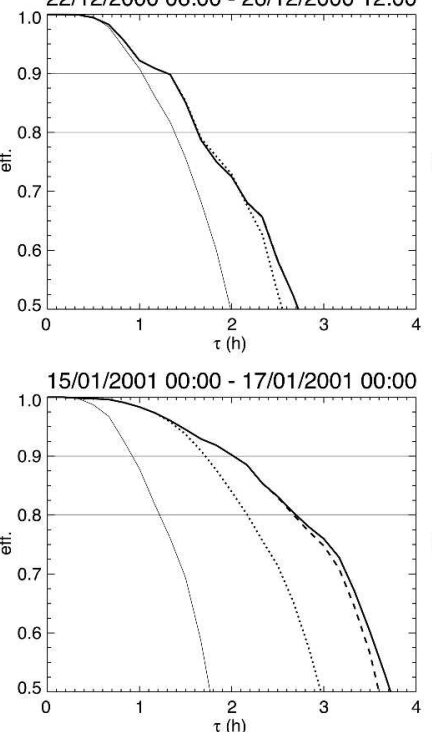

19/07/2001 00:00- $20 / 07 / 2001112: 00$

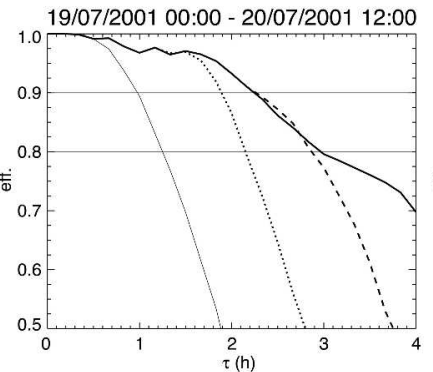

15/11/2001 06:00 - 17/11/200100:00

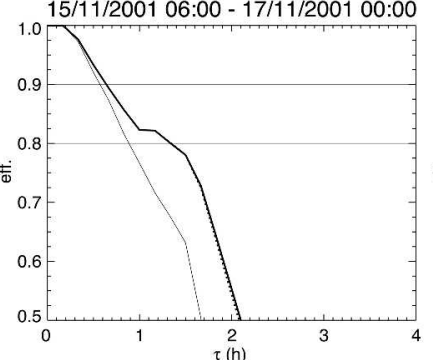

RIPOLL BASIN $\left(65 \mathrm{~km}^{2}\right)$
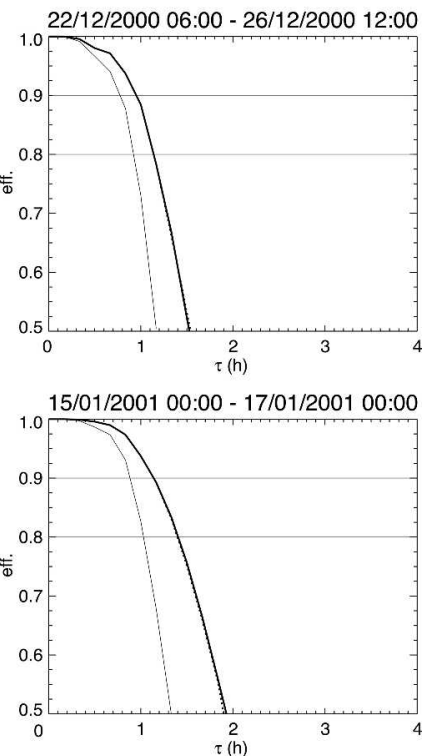

(19/07/2001 00:00-20/07/200112:00

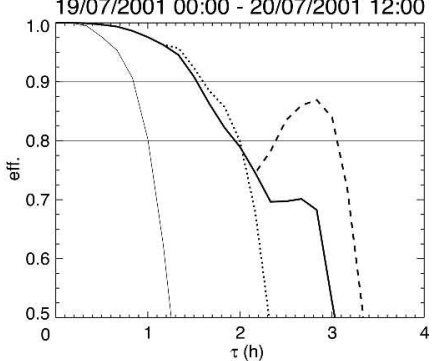

$15 / 11 / 200106: 00-17 / 11 / 200100: 00$

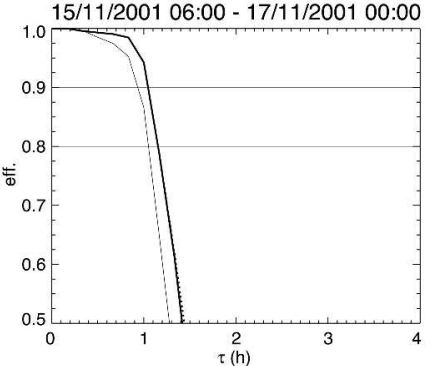

No forecast

1h-forecas

3h-forecast

FIG. 12. Evolution of the Nash efficiency of the forecasted hydrographs as a function of the duration of the Lagrangian persistence forecast input to the model, $\theta$. Different lines correspond to different durations: $0 \mathrm{~h}$ (thin line), $1 \mathrm{~h}$ (dotted line), $2 \mathrm{~h}$ (dashed line), and $3 \mathrm{~h}$ (continuous thick line).

\section{a. Duration of the forecast}

Figure 12 shows the $\tau$-efficiency curves obtained using Lagrangian persistence rainfall forecasts of different durations, $\theta=0,1,2,3 \mathrm{~h}$ (similar results-not presented-were obtained with the rainfall forecasts generated with S-PROG). In general, we can see some improvement when $\theta=2 \mathrm{~h}$ (with respect to $\theta=1 \mathrm{~h}$ ) in the Besòs and in the Mogent basins (in the Ripoll basin, almost no difference may be appreciated for $\theta>1 \mathrm{~h}$ ). However, curves obtained with $\theta=2 \mathrm{~h}$ and $\theta=3 \mathrm{~h}$ are very similar for $\tau<\tau_{0.80}$ (note that by construction, these two curves are identical for $\tau<2 \mathrm{~h}$ ). This means that while there is some useful information in the rainfall fields forecasted for lead times between 1 and $2 \mathrm{~h}$, the average quality of the fields obtained for lead times between 2 and $3 \mathrm{~h}$ is rather poor and useless to improve the quality of forecasted flows obtained with the hydro- 
logical model. Therefore, as rainfall forecasts of $\theta>2 \mathrm{~h}$ do not improve the quality of simulated flows, it was considered that, in the studied basins, setting $\theta=2 \mathrm{~h}$ is sufficient, and thus results presented below were obtained with $2 \mathrm{~h}$ of rainfall forecasts.

\section{$b$. Influence of a stationary motion field in the forecasts}

This part of the study consisted of generating SPROG forecasts for a certain time step, $t+n$, with the particularity of advecting the forecasted fields $\hat{Z}(t+n$ -1) of Eq. (5) according to an "updated" motion field; in Eq. (5), $\mathbf{v}(t)$ is thus substituted by the known future motion field $\mathbf{v}(t+n)$, which is derived from the actually observed radar fields at time $t+n, Z(t+n-1)$, and $Z(t+n)$. Therefore, in this simulation, the advection is done using the best possible motion field at that time, which means that the difference with the perfect forecast is no longer due to the stationarity of the motion field.

The quality of forecasted hydrographs obtained using S-PROG with this updated motion is presented in Fig. 13 (dotted line). They should be compared against forecasted hydrographs simulated with the habitual configuration of S-PROG [with a stationary motion field estimated at $t$ from the last observed radar fields, $Z(t-$ 1) and $Z(t)$; solid line]. From the results, no significant improvements in the quality of the forecasted hydrographs could be appreciated when the updated motion field is used to advect the most recent radar field.

\section{c. Impact of the forecasted mean areal precipitation}

The effect of a good estimation of the mean areal rainfall over the basin is now explored. To do it, at each time step forecasted rainfall fields are now replaced by series of $\theta=2 \mathrm{~h}$ of uniform rainfall fields with intensity equal to the actual observed mean areal rainfall over the studied basin.

The objective is now to build the forecasted hydrograph that would be obtained if the right mean areal rainfall were known in advance, without taking into account the role of the distribution of the rainfall over the basin (the evolution of the resulting efficiency of the flow forecasts with $\tau$ is plotted with dashed line in Fig. 13).

Using these rainfall fields as forecast allowed us to significantly improve previous results. In general, the efficiency of these forecasted hydrographs keeps over 0.90 while $\tau$ is shorter than the lag time plus $2 \mathrm{~h}$ (which is the length of the rainfall forecasts, $\theta$ ). At this point, there is a break in the efficiency line, and the quality of the forecasted hydrographs decays rapidly.
This analysis also allowed us to quantify the importance of a good description of the spatial distribution of the precipitation field over the basins. This can be done by comparing the Nash efficiency $\tau$ curves that resulted from using uniform fields against the results obtained by using $\theta=2 \mathrm{~h}$ of actually observed radar scans as rainfall forecast (dashed-dotted curve in Fig. 13; notice that it is parallel with a delay of $2 \mathrm{~h}$ to the curve obtained without rainfall forecast). The distance between dashed and dashed-dotted curves is only explained by the spatial description of the precipitation field. It can be seen that these differences were less important for the Ripoll basin $\left(65 \mathrm{~km}^{2}\right)$ than for the Mogent and Besòs basins (180 and $1015 \mathrm{~km}^{2}$ ), where a good spatial description of the rainfall inputs allowed the model to generate better-forecasted hydrographs.

These results partially agree with the conclusions of Obled et al. (1994), who found that the accuracy of the volume of precipitation over the basin leads to significant improvements in the resulting hydrographs (simulated with a rainfall-runoff model also based on TOPMODEL). However, they did not find improvements in simulated hydrographs when they used distributed precipitation fields with a better spatial description and concluded that the only purpose of using them is to improve the accuracy of the incoming rainfall volume over the basin rather than taking into account any interaction between the incoming rainfall field and the simulated mechanisms of flow generation. In our case, the bigger the basin the more important these interactions become, being of little importance for the case of the Ripoll basin [which has an area similar to the $71 \mathrm{~km}^{2}$ of the basin studied by Obled et al. (1994)]. Since bigger basins are supposed to exert a smoothing effect that would reduce the importance of the spatial distribution of rainfall, these results may seem counterintuitive. However, this effect can predominate when precipitation affects the main part of the catchment, while when the rainfall field is composed by small patterns (such as very intense convective cells) there are two main factors that could explain the importance of the rainfall distribution over the basin: (a) differences due to the localization of small rainfall patterns over the basin with respect to the uniform field are more important in bigger basins, which may result in significant differences in the response time of the basin, as suggested by Obled et al. (1994), and (b) differences between the mean areal rainfall calculated over the basin and the rates of each individual rainfall pattern (e.g., of a small convective cell) also tend to be higher in bigger basins, which in combination with the nonlinear processes of runoff generation may produce quite different hydrographs. 
BESÒS BASIN (1015 km²)
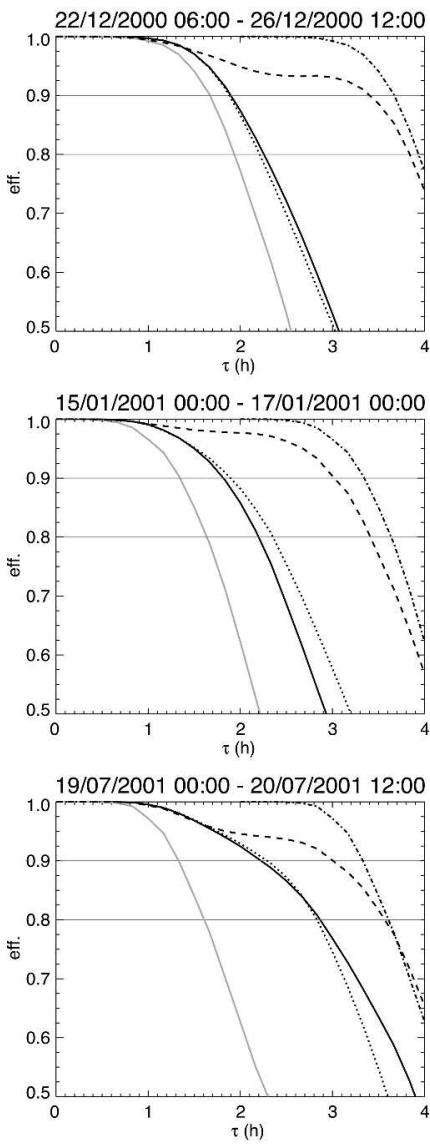

15/11/2001 06:00 - 17/11/2001 00:00

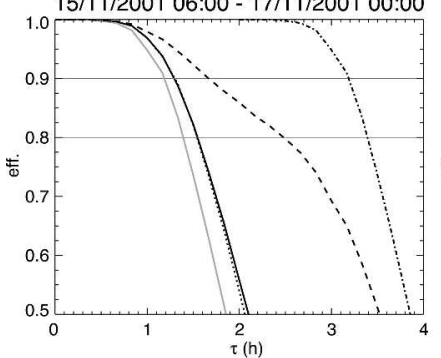

MOGENT BASIN $\left(180 \mathrm{~km}^{2}\right)$

22/12/2000 06:00 - 26/12/2000 12:00
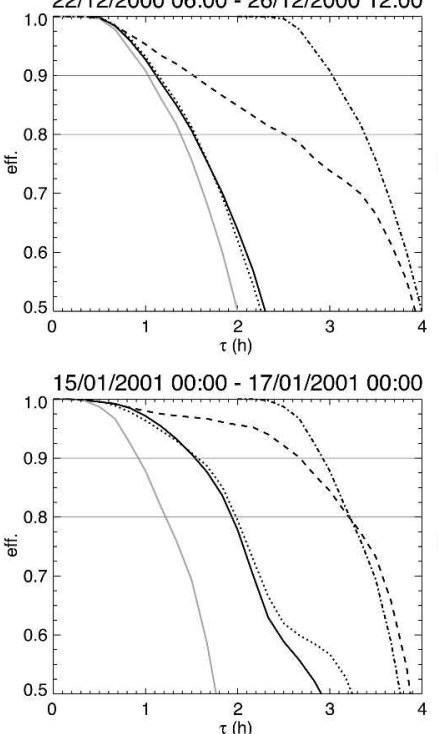

19/07/2001 00:00 - 20/07/2001 12:00

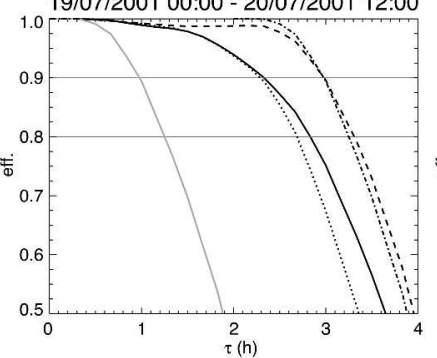

15/11/2001 06:00 - 17/11/200100:00

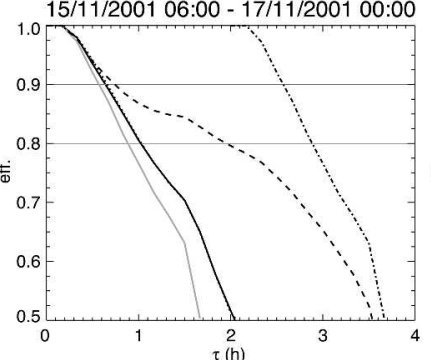

RIPOLL BASIN $\left(65 \mathrm{~km}^{2}\right)$
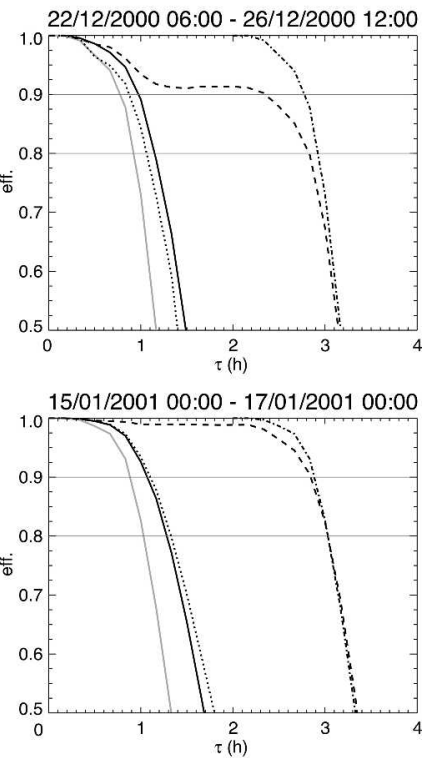

19/07/2001 00:00 - 20/07/2001 12:00

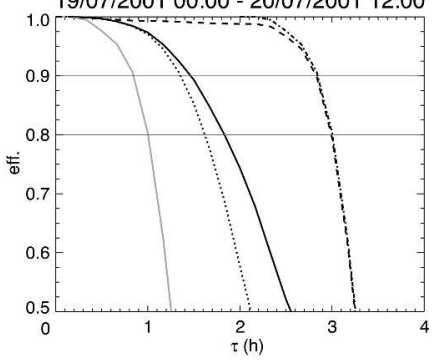

$15 / 11 / 200106: 00-17 / 11 / 200100: 00$

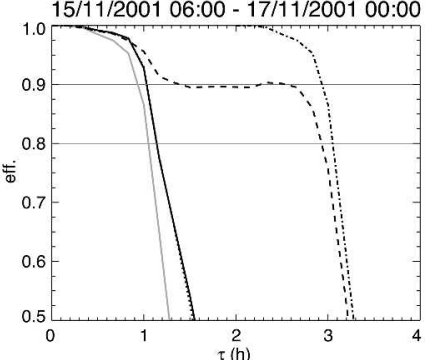

No forecast

S-PROG

Updated motion

- Mean field

- Dist. field

FIG. 13. Evolution of the Nash efficiency of the forecasted hydrographs as a function of the anticipation with which hydrographs are simulated, $\tau$. Different lines represent hydrographs simulated with precipitation fields forecasted with different techniques: with no forecast (gray line), by S-PROG (solid line), by S-PROG using "updated motion fields" (dotted line), with $\theta=2 \mathrm{~h}$ of an uniform field with the observed mean areal rainfall (dashed line), and also with $\theta=2 \mathrm{~h}$ of actual radar scans (dashed-dotted line).

A dependency on the type of precipitation and nature of the event could also be observed. For the most stratiform case of 15 January 2001 differences between using uniform or properly distributed precipitation fields were much less important than the differences found for the case of the convective event of
15 November 2001, with influential local cells affecting the basin (for the mixed case of 19 July 2001, intermediate differences were found).

Finally, the main conclusion from the analyzed results is that one of the most important points to improve the quality of forecasted hydrographs is a good 
estimate of the mean areal rainfall of the forecasted fields over the basin.

\section{Summary and conclusions}

In the present study the radar-based nowcasting technique S-PROG was implemented in a Mediterranean area using data from different events representative of the climatic characteristics of the studied region. The main purpose was to evaluate the usefulness of SPROG for hydrological purposes. This validation was carried out from two different perspectives: (a) in terms of the point-to-point comparison between forecasted and measured rainfall rates, and (b) from the point of view of the hydrographs simulated using the forecasted rainfall fields as input of a distributed rainfall-runoff model.

In terms of rainfall, S-PROG produced betterforecasted fields than Lagrangian and Eulerian persistence in all cases (only some more sensitivity to the quality of the motion field was observed for the extrapolation techniques in smaller domains). On the other hand, the hydrological validation showed that the use of a nowcasting technique based on radar data allows us to significantly improve the quality of forecasted hydrographs. For example, the anticipation with which flows could be estimated with enough quality was extended by between 10 and $80 \mathrm{~min}$ in the Besòs basin. This could be considered a notable improvement in the fast response basins of the Mediterranean areas (which in many cases have lag times between 1 and $2 \mathrm{~h}$ ). However, the results obtained using S-PROG were not significantly better than the results obtained with a much simpler nowcasting technique (Lagrangian persistence, which does not include small-scale filtering).

In all cases, it has been noticed that the nature of the event (especially the type of precipitation and the degree of spatial organization of the rainfall field) has an important effect on the quality of the forecasted flow estimates. In particular, as the analyzed forecasting techniques take into account neither the possibility of orographic enhancement nor the short life cycle of small convective cells, results obtained in the events where these effects were significant are rather poor.

The influence of different factors of the forecasted rainfall fields that could affect the quality of the forecasted hydrographs was also analyzed in section 5: results showed that, in the studied domain, using series of $2 \mathrm{~h}$ of rainfall forecasts is enough, as this allowed us to improve the forecasted flows obtained inputting 1-h series, while using longer rainfall forecasts did not introduce any useful information to the model. On the other hand, it has been found that no significant improvement in forecasted discharges is obtained when the best possible motion field was used to advect forecasted rainfall fields (instead of imposing stationarity). Finally, we can conclude that the crucial factor to improve the quality of forecasted flows is the quality of the forecasted mean areal rainfall over the basin, as shown by inputting series of uniform rainfall fields with the observed mean areal rainfall into the model. This analysis also allowed us to quantify the effect of the spatial distribution of the rainfall field over the basin, which was found to be more important in bigger basins.

Since it has been shown that the quality of the forecasted precipitation fields significantly decreases for lead times over $1 \mathrm{~h}$, it could be interesting to look for different alternatives that may lead to improved forecasted hydrographs. Germann and Zawadzki (2002) proposed the use of composite images from a radar network instead of single-radar data to increase the size of the rainfall domain. This will provide information about entire mesoscale and synoptic-scale phenomena, leading us to avoid the lack of information caused by the advection of areas out of the radar domain in case of high speeds. On the other hand, it also will result in better estimations of velocity fields (less affected by border effects in the area of interest). An alternative approach for the nowcasting technique would be the generation of probabilistic rainfall forecasts [using, e.g., the techniques proposed by Germann and Zawadzki (2004) or Seed and Bowler (2003)] as input of the rainfall-runoff model, in order to produce stochastic forecasted hydrographs. This could be a way to overcome the limitations of a deterministic nowcasting technique coupled with a rainfall-runoff model for producing useful rainfall fields at lead times over $2 \mathrm{~h}$.

From a different perspective, interesting new ideas that focus on coupling NWP and distributed rainfallrunoff models in medium-sized basins of few thousands of square kilometers (see, e.g., Jasper et al. 2002) seem to be a promising alternative to further extend the anticipation with which hydrographs may be forecasted.

Acknowledgments. We would like to express our thanks to Dr. Alan Seed for fruitful discussions on the implementation of S-PROG and its usefulness in flood forecasting and to Prof. Geoff Pegram for a first review of this paper. The Spanish Institute of Meteorology provided radar data (thanks are due to Ramon Pascual for his availability). This work has been done in the framework of the EC projects VOLTAIRE EC (EVK2-CT-2002-00155) and FLOODSITE (GOCECT-2004-505420). 


\section{REFERENCES}

Bellon, A., and I. Zawadzki, 1994: Forecasting of hourly accumulations of precipitation by optimal extrapolation of radar maps. J. Hydrol., 157, 211-233.

Beven, K., and M. J. Kirkby, 1979: A physically-based variablecontributing area model of basin hydrology. Hydrol. Sci. Bull., 24, 27-53.

Borga, M., 2002: Accuracy of radar rainfall estimates for streamflow simulation. J. Hydrol., 267, 26-39.

— , E. N. Anagnostou, and E. Frank, 2000: On the use of realtime radar rainfall estimates for flood prediction in mountainous basins. J. Geophys. Res., 105, 2269-2280.

Carpenter, T. M., K. P. Georgakakos, and J. A. Sperfslagea, 2001: On the parametric and NEXRAD-radar sensitivities of a distributed hydrologic model suitable for operational use. J. Hydrol., 253, 169-193.

Corral, C., 2004: Desenvolupament d'un model hidrològic per incorporar informació del radar meteorològic. Aplicació operacional a la conca del riu Besòs. Ph.D. dissertation, Universitat Politècnica de Catalunya, 175 pp.

—, D. Sempere-Torres, M. Berenguer, and I. Escaler, 2001: A distributed rainfall runoff model integrated in an operational hydrometeorological forecasting system in Catalunya based in weather radar. Preprints, Fifth Int. Symp. on Hydrological Applications of Weather Radar, Kyoto, Japan, Japanese Disaster Prevention Research Institute, 407-412.

—_, M. Berenguer, D. Sempere-Torres, and I. Escaler, 2002: Evaluation of a conceptual distributed rainfall-runoff model in the Besòs catchment in Catalunya using radar information. Preprints, Second European Conf. on Radar Meteorology, Delft, Netherlands, European Meteorological Society, 409415.

Delrieu, G., and J. D. Creutin, 1995: Simulation of radar mountain returns using a digitized terrain model. J. Atmos. Oceanic Technol., 12, 1038-1049.

Dolcine, L., H. Andrieu, D. Sempere-Torres, and J.-D. Creutin, 2001: Flash flood forecasting with a coupled precipitation model in a mountainous Mediterranean basin. J. Hydrol. Eng., 6, 1-10.

Faurès, J. M., D. C. Goodrich, D. A. Woodlhiser, and S. Sorooshian, 1995: Impact of small-scale spatial rainfall variability on runoff modelling. J. Hydrol., 173, 309-326.

Germann, U., and I. Zawadzki, 2002: Scale-dependence of the predictability of precipitation from continental radar images. Part I: Description of the methodology. Mon. Wea. Rev., 130, 2859-2873.

— , and — 2004: Scale-dependence of the predictability of precipitation from continental radar images. Part II: Probability forecasts. J. Appl. Meteor., 43, 74-89.

Giannoni, F., J. A. Smith, Y. Zhang, and G. Roth, 2003: Hydrologic modeling of extreme floods using radar rainfall estimates. Adv. Water Resour., 26, 195-203.

Gourley, J. J., and B. E. Vieux, 2003: A hydrologic approach to evaluating quantitative precipitation estimates. Preprints, 31st Conf. on Radar Meteorology, Seattle, WA, Amer. Meteor. Soc., 714-717.

Jasper, K., J. Gurtz, and H. Lang, 2002: Advanced flood forecasting in Alpine watersheds by coupling meteorological observations and forecasts with a distributed hydrological model. $J$. Hydrol., 267, 40-52.

Kouwen, N., A. Bingeman, A. Bellon, and I. Zawadzki, 2004: Operational issues: Real-time correction and hydrological validation of radar data. Preprints, Sixth Int. Symp. on Hy- drological Applications of Weather Radar, Melbourne, Australian Bureau of Meteorology, CD-ROM.

Krajewski, W., K. P. Venkataraman, K. Georgakakos, and S. C. Jain, 1991: A Monte Carlo study of rainfall sampling effect on a distributed catchment model. Water Resour. Res., 27, 119128.

Li, L., W. Schmid, and J. Joss, 1995: Nowcasting of motion and growth of precipitation with radar over a complex orography. J. Appl. Meteor., 34, 1286-1300.

Mecklenburg, S., V. A. Bell, D. S. Carrington, A. M. Cooper, R. J. Moore, and C. E. Pierce, 2001: Interfacing COTREC-derived rainfall forecasts with the rainfall-runoff model PDM. Preprints, Fifth Int. Symp. on Hydrological Applications of Weather Radar, Kyoto, Japan, Japanese Disaster Prevention Research Institute, 457-463.

Mockus, V., 1957: Use of storm and watersheds characteristics in synthetic hydrograph analysis and application. U.S. Dept. of Agriculture, Soil Conservation Service.

Nash, J. E., 1957: The form of instantaneous unit hydrograph. Hydrol. Sci. Bull., 3, 114-121.

_ , and J. V. Sutcliffe, 1970: River flow forecasting through conceptual models. 1. A discussion of principles. J. Hydrol., 10, 282-290.

Obled, C., J. Wendling, and K. Beven, 1994: The sensitivity of hydrological models to spatial rainfall patterns: An evaluation using observed data. J. Hydrol., 159, 305-333.

Ogden, F. L., and P. Y. Julien, 1994: Runoff model sensitivity to radar rainfall resolution. J. Hydrol., 158, 1-18.

Pellarin, T., G. Delrieu, G.-M. Saulnier, H. Andrieu, B. Vignal, and J.-D. Creutin, 2002: Hydrologic visibility of weather radar systems operating in mountainous regions: Case study for the Ardeche Catchment (France). J. Hydrometeor., 3, 539555 .

Pessoa, M. L., L. B. Raael, and R. W. Earle, 1993: Use of weather radar for flood forecasting in the Sieve river basin: A sensitivity analysis. J. Appl. Meteor., 32, 462-475.

Rawls, W. J., L. R. Ahuja, D. L. Brakensiek, and A. Shirmohammadi, 1992: Infiltration and soil water movement. Handbook of Hydrology, D. R. Maidment, Ed., McGraw-Hill, 5.1-5.51.

Rinehart, R. E., and E. T. Garvey, 1978: Three-dimensional storm motion detection by conventional weather radar. Nature, 273, 287-289.

Sánchez-Diezma, R., D. Sempere-Torres, J. D. Creutin, I. Zawadzki, and G. Delrieu, 2001a: Factors affecting the precision of radar measurement of rain. An assessment from a hydrological perspective. Preprints, 30th Int. Conf. on Radar Meteorology, Munich, Germany, Amer. Meteor. Soc., 573575.

, - G. Delrieu, and I. Zawadzki, 2001b: An improved methodology for ground clutter substitution based on a preclassification of precipitation types. Preprints, 30th Int. Conf. on Radar Meteorology, Munich, Germany, Amer. Meteor. Soc., 271-273.

Seed, A. W., 2003: A dynamic and spatial scaling approach to advection forecasting. J. Appl. Meteor., 42, 381-388.

, and N. Bowler, 2003: A model to generate stochastic nowcasts of rainfall. Preprints, 31st Conf. on Radar Meteorology, Seattle, WA, Amer. Meteor. Soc., 704-708.

Sempere-Torres, D., J. M. Porrà, and J. D. Creutin, 1997: Characterization of rainfall properties using the drop size distribution: Application to autumn storms in Barcelona. Preprints, WMO-INM Int. Conf. on Cyclones and Hazardous 
Weather in the Mediterranean Area, Mallorca, Spain, Instituto Nacional de Meteorología, 621-628.

$[, \ldots$, and $—$ 1998: Experimental evidence of a general description for raindrop size distribution properties. J. Geophys. Res., 103, 1785-1797.

_ C. Corral, P. Malgrat, and J. Raso, 1999: Use of weather radar for combined sewer overflows monitoring and control. J. Environ. Eng., 125, 372-380.

—, R. Sánchez-Diezma, M. Berenguer, R. Pascual, and I. Zawadzki, 2003: Improving radar rainfall measurement stability using mountain returns in real time. Preprints, 31st Conf. on Radar Meteorology, Seattle, WA, Amer. Meteor. Soc., 220-221.

Shah, S. M. S., P. E. O'Connell, and R. M. Hosking, 1996: Modeling the effects of spatial variability in rainfall on catchment response. 2. Experiments with distributed and lumped models. J. Hydrol., 175, 89-111.

Sun, X., R. G. Mein, T. D. Keenan, and J. F. Elliot, 2000: Flood estimation using radar and raingauge data. J. Hydrol., 239, 4-18.

Vieux, B. E., and P. B. Bedient, 2004: Assessing urban hydrologic prediction accuracy through event reconstruction. J. Hydrol., 299, 217-236.

Wilson, C. B., J. B. Valdes, and I. Rodriguez-Iturbe, 1979: On the influence of the spatial distribution of rainfall on storm runoff. Water Resour. Res., 15, 321-328.

Wilson, J., 2003: Thunderstorm nowcasting: Past, present and future. Preprints, 31st Conf. on Radar Meteorology, Seattle, WA, Amer. Meteor. Soc., J13-J19.

- N. A. Crook, C. K. Mueller, J. Sun, and M. Dixon, 1998: Nowcasting thunderstorms: A status report. Bull. Amer. Meteor. Soc., 79, 2079-2099.

Winchell, W., H. V. Gupta, and S. Sorooshian, 1998: On the simulation of infiltration- and saturation-excess runoff using radar-based rainfall estimates: Effects of algorithm uncertainty and pixel aggregation. Water Resour. Res., 34, 2655-2670.

WMO, 1992: Simulated real-time intercomparison of hydrological models. OHR 38, 241 pp.

Wyss, J., E. R. Williams, and R. L. Bras, 1990: Hydrologic modeling of New England river basins using radar rainfall data. $J$. Geophys. Res., 95, 2143-2152. 